Ann. Abeille, I966, 9 (2), II5-I52.

\title{
DIE PHÄNOANALYSE DER ABDOMINAL-TERGITE VON DROHNEN VERSCHIEDENER GEOGRAPHISCHER RASSEN DER HONIGBIENE (APIS MELLIFICA L.) UND IHRER KREUZUNGEN (1)
}

\author{
J. KULINČEVIĆ \\ Institut für Landwirtschaftiche Zoologie und Bienenkunde \\ der Rheinischen Friedrich Wilhelms-Universität, Bonn (Allemagne)
}

\section{SOMMAIRE}

L'auteur a procédé à la phéno-analyse de la pigmentation des Tergites abdominaux chez I 300 mâles d'abeilles appartenant à 9 races géographiques différentes et à divers croisements réalisés par insémination artificielle. La pigmentation présentée par les différentes races peut entrer dans un système de to classes, sauf en ce qui concerne $A . m$. ligustica qui nécessite une échelle particulière. L'analyse de la pigmentation des descendants mâles de croisements de races laisse supposer une base polygénique de la formation des dessins. Il n'y a pas de matroclinie. L'influence dominante du partenaire le plus foncé a été mise en évidence.

\section{A. - EINLEITUNG}

Die Pigmentierung der Abdominal-Tergite bei Biene und Drohn sahen bereits GERSTÄCKER (I862) und BUTTEL-REEPEN (IgO6) als wertvolles taxonomisches Merkmal bei der Abgrenzung der geographischen Bienenrassen an. Bei der Charakterisierung der Bienenrassen durch die imkerlichen Praktiker sprach man auch, bedingt durch die dominierende Färbung des Abdomens, von der Apis mellifica mellifica als der schwarzen deutschen Biene, von der Apis mellifica ligustica als der gelben italienischen Biene.

Boveri (I9I5) und ZANDER (I92I) begannen, die grob morphologische Beurteilung der Abdominal-Pigmentierung durch Anfertigung und Auswertung von Abdominal-Präparaten zu verfeinern. Weitere Untersuchungen dieser Art iber die Pigmentverteilung in den Tergiten der Drohnen führten ARMBruster (I923) und ZANDER (I923) durch. ARMBruster lehnte eine Rasseneinteilung nach Farbmerk-

(1) Dissertation an der Landwirtschaftlichen Fakultät der Univerität. Bonn vom 9. Dez• 1965 
malen des Abdomens ab und stellte eine einheitliche Klassifizierung, die für alle Rassen guiltig sein sollte, durch Beurteilung des dritten Tergits auf. ZaNDER hingegen hob die Bedeutung der Abdominalfärbung als Rassenmerkmal hervor und charakterisierte in seiner Klassifikation spezielle Mellifica-, Ligustica- und Cypria-Typen.

Die Frage nach der Bedeutung der abdominalen Pigmentierung für die Taxonomie der Biene wurde erneut von GoETzE (I95I) durch seine detaillierte Analyse der Musterbildungen bei Ligustica-Drohnen aufgegriffen. Weiterhin lierferten RoBERTS (I950), Giavarini (I953), van den BERG (I957) und Ru'T'TNER (I963) Beiträge zu diesem Thema.

Die Bewertung von Pigmentmustern fïr die Rassen-Diagnose wird erschwert durch das starke Auftreten unkontrollierter Bastardierung der Bienenrassen auf Grund der Einfuhr von ortsfremden Bienen aus ökonomischen Gründen durch die Bienenzüchter.

Um vor der in naher Zukunft zu erwartenden völligen Bastardierung und Verdrängung geographischer Bienenrassen durch wirtschaftlich überlegene noch einen Überblick der im europäisch-mediterranen Bereich vorhandenen endemischen Bienenrassen mit ihren Zeichnungsmustern zu geben, wurden in der vorliegenden Arbeit Drohnenproben verschiedener geographischer Herkunft unter Beachtung ihrer Pigmentierung ausgewertet.

Mit Hilfe der von Mackensen und Roberts (I948) vervollkommneten Methode der instrumentellen Samenïbertragung konnten von einigen im hiesigen Institut vorhandenen Bienenrassen kontrollierte Kreuzungen vorgenommen werden und durch ihre Pigmentmuster-Analyse die Vorarbeiten für eine eingehendere Analyse der polygenen Basis dieser Musterausbildung geleistet werden.

\section{B. - DIE KIASSIFIKATION DES ABDOMINALEN ZEICHNUNGSMUSTERS}

\section{VON DROHNEN VERSCHIEDENER GEOGRAPHISCHER RASSEN}

\section{I. - ARbeitSMETHODEN}

\section{a) Material und Methode}

Bei den Drohnen der Honigbiene haben wir es normalerweise wegen ihrer azygoten Herkunft mit "personifizierten Gameten " (ARMBruster, I9I9) zu tun. Die Drohnennachkommenschaft jeder Königin stellt ein Spektrum aller ihrer Erbanlagen ohne Verschleierung durch die Wirkung eines väterlichen Genoms dar.

Material. Das Drohnenmaterial für meine Untersuchung (Tab. I) wurde zum Teil in konservierter Form aus den Ursprungsgebieten (Herkunft siehe in Abb. I) der Bienenrassen bezogen ( ${ }^{1}$, zum Teil stand es in der Sammlung des hiesigen Instituts in feucht oder trocken konservierter Form zur Verfügung, oder war von lebenden Völkern des Instituts-Bienenstandes zu erlangen.

Diejenigen Proben, die ich zugeschickt erhielt, sollen nach Mitteilung der Züchter jeweils von einer Königin abstammen, doch muss bei normaler Aufstellung der Völker immer mit einem unterschiedlichen Ausmass an Verflug von Arbeiterinnen aber auch von Drohnen gerechnet werden. Dieser Tatbestand ist für die Festlegung der rassetypischen Pigmentierung jedoch nicht entscheidend. Sicher sind die Proben, die von Instituts-Völkern entnommen wurden, frei von Verflug oder Mischung, da die verdeckelte Drohnenbrut in einer Absperrgitter-Wabentasche gehalten wurde, gedankt.

(1) Den in Tab. I namentlich angeführten Kollegen sei für die Übersendung des Materials an dieser Stelle 
und die Bienen diese Brut nur durch das Absperrgitter pflegen konnten. Geschlüpfte Drohnen entnahm ich nach 4-6 Tagen und konservierte die Proben in $70 \%$ igem Alkohol. Darin wurden sie bis zur Bearbeitung durchschnittlich 2 Monate belassen. Wichtig bei der Konservierung war die Erhaltung der Herauslösbarkeit der Muskulatur des Abdomens, ohne dass ein Verlust an Pigment bei den Tergiten auftrat.

TABLEAU I

Vue d'ensemble des mâles étudiés

TABELLE I

Übersicht der untersuchten Drohnenproben

\begin{tabular}{|c|c|c|c|c|c|c|}
\hline Probe & Geogr. Rasse & Jahr & Land & Züchter & Anzahl & Konserv. (\%) \\
\hline $\begin{array}{l}L_{1} \\
L_{2} \\
L_{3} \\
L_{4} \\
L_{5}\end{array}$ & $\begin{array}{l}\text { Ligustica } \\
\text { Ligustica } \\
\text { Ligustica } \\
\text { Ligustica } \\
\text { Ligustica }\end{array}$ & $\begin{array}{l}1964 \\
1964 \\
1963 \\
1964 \\
1964\end{array}$ & $\begin{array}{l}\text { Ital. } \\
\text { Ital. } \\
\text { Dtld. } \\
\text { Dtld. } \\
\text { Dtld. }\end{array}$ & $\begin{array}{l}\text { Piana } \\
\text { Tortora } \\
\text { Inst. Bonn } \\
\text { Inst. Bonn } \\
\text { Inst. Bonn }\end{array}$ & $\begin{array}{l}62 \\
40 \\
50 \\
94 \\
50\end{array}$ & $\begin{array}{cc}70 & \text { Alk. } \\
70 & \text { Alk. } \\
70 & \text { Alk. } \\
70 & \text { Alk. } \\
70 & \text { Alk. }\end{array}$ \\
\hline $\begin{array}{l}S_{1} \\
S_{2} \\
S_{3} \\
S_{4}\end{array}$ & $\begin{array}{l}\text { Sahariensis } \\
\text { Sahariensis } \\
\text { Sahariensis } \\
\text { Sahariensis }\end{array}$ & $\begin{array}{l}1962 \\
1963 \\
1962 \\
1964\end{array}$ & $\begin{array}{l}\text { Marok. } \\
\text { Marok. } \\
\text { Marok. } \\
\text { Dtld. }\end{array}$ & $\begin{array}{l}\text { Haccour } \\
\text { Haccour } \\
\text { Haccour } \\
\text { Inst. Bonn }\end{array}$ & $\begin{array}{l}34 \\
38 \\
92 \\
64\end{array}$ & $\begin{array}{cl}70 & \text { Alk. } \\
70 & \text { Alk. } \\
70 & \text { Alk. } \\
70 & \text { Alk. }\end{array}$ \\
\hline $\begin{array}{l}F_{1} \\
F_{2} \\
F_{3}\end{array}$ & $\begin{array}{l}\text { Fasciata } \\
\text { Fasciata } \\
\text { Fasciata }\end{array}$ & $\begin{array}{l}196^{\prime} \\
1964 \\
1952\end{array}$ & $\begin{array}{l}\text { Ägypt. } \\
\text { Agypt. } \\
\text { Dtld. }\end{array}$ & $\begin{array}{l}\text { El Banby } \\
\text { El Banby } \\
\text { Meyerhoff }\end{array}$ & $\begin{array}{l}53 \\
35 \\
26\end{array}$ & $\begin{array}{l}70 \text { Alk. } \\
70 \text { Alk. } \\
\text { Trocken }\end{array}$ \\
\hline C & Cypria & $19^{\prime} \div 3$ & Dtld. & Meyerhoff & 31 & Trocken \\
\hline $\begin{array}{l}P_{1} \\
P_{2} \\
P_{3}\end{array}$ & $\begin{array}{l}\text { Persica } \\
\text { Persica } \\
\text { Persica }\end{array}$ & $\begin{array}{l}1964 \\
1964 \\
196^{\prime}\end{array}$ & $\begin{array}{l}\text { Pers. } \\
\text { Pers. } \\
\text { Pers. }\end{array}$ & $\begin{array}{l}\text { Saremi } \\
\text { Saremi } \\
\text { Saremi }\end{array}$ & $\begin{array}{r}5 \\
5 \\
11\end{array}$ & $\begin{array}{cc}70 & \text { Alk. } \\
\text { 70 } & \text { Alk. } \\
\text { 70 } & \text { Alk. }\end{array}$ \\
\hline$A$ & Armenica & 1961 & Russl. & Gluschkow & 101 & 70 Alk. \\
\hline K & Cancasica & 1952 & Dtld. & Wohlgemuth & 31 & Trocken \\
\hline $\begin{array}{l}C \mathrm{a}_{1} \\
\mathrm{Ca}_{2} \\
\mathrm{Ca}_{3}\end{array}$ & $\begin{array}{l}\text { Carnica } \\
\text { Carnica } \\
\text { Carnica }\end{array}$ & $\begin{array}{l}1964 \\
1952 \\
196 \%\end{array}$ & $\begin{array}{c}\text { Dtld. } \\
\text { Österr. } \\
\text { Jugos. }\end{array}$ & $\begin{array}{c}\text { Inst. Bonn } \\
\text { Graz } \\
\text { Banat }\end{array}$ & $\begin{array}{l}33 \\
31 \\
81\end{array}$ & $\begin{array}{l}70 \text { Alk. } \\
\text { Trocken } \\
70 \text { Alk. }\end{array}$ \\
\hline $\begin{array}{l}N_{1} \\
N_{2}\end{array}$ & $\begin{array}{l}\text { Mellifica } \\
\text { Mellifica }\end{array}$ & $\begin{array}{l}1966^{\prime} \\
1952\end{array}$ & $\begin{array}{l}\text { Dtld. } \\
\text { Dtld. }\end{array}$ & $\begin{array}{l}\text { Inst. Bonn } \\
\text { Inst. Bonn }\end{array}$ & $\begin{array}{l}33 \\
31\end{array}$ & $\begin{array}{l}70 \text { Alk. } \\
\text { Trocken }\end{array}$ \\
\hline
\end{tabular}

Methode. Für meine Untersuchung musste ich das Drohnen-Abdomen von der Muskulatur und den anderen abdominalen Organen befreien. Dazu wurden die Abdomina von der Bauchseite her so geöffnet, dass alle Tergite zusammenhängend blieben und die Organe mechanisch entfernt werden konnten. Die so präparierten und abgetrockneten Abdomina bewahrte ich vor Licht geschützt in Milchsäure auf. Die in diesem Medium aufbewahrten Präparate standen ohne Veränderung ausreichend weich und gleichmässig durchsichtig für die Zeichnung und Klassifizierung zur Verfügung.

Getrocknete Drohnen aus der Instituts-Sammlung erforderten eine andere Behandlung. Die abgetrennten Abdomina wurden Io- $12 \mathrm{~h}$ in warmes Wasser gelegt, danach wurden sie 24 Stunden lang in $5 \%$ iger Kalilauge bei $30^{\circ} \mathrm{C}$ im Wärmeschrank belassen. Die Kalilauge bewirkte eine $\mathrm{Er}$ weichung der Abdomina, hatte aber auch als Nachteil eine schwache Herauslösung des schwar- 


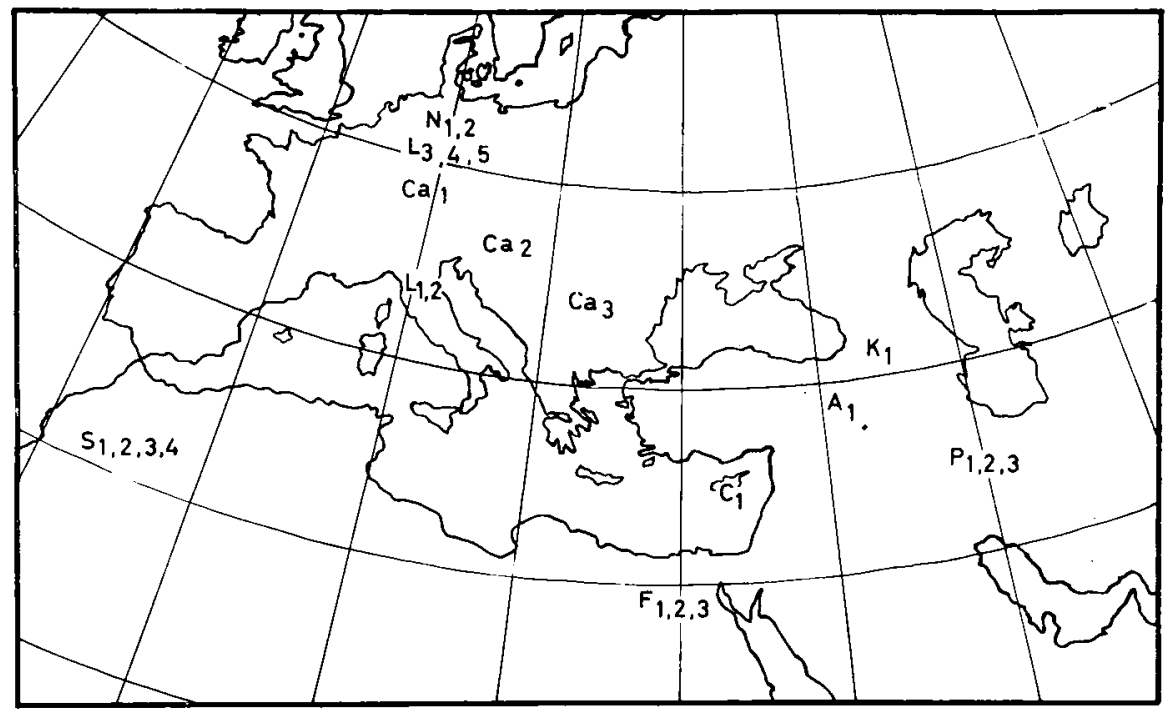

Aвв. г. - Geographische IIerkuntt der Drohnenproben sur Untersuchung der abdominalen Zeichnungsmutsier FIG. I. - I'ronenance géographique des mâles pour l'élude du dessin abdominul

TABLEAU 2

Comparaison de la terminologie de différents auleurs dans la description des tergites mâles

TABEI,I, 2

Ein Vergleich der Terminologie verschiedener Autoren bei Beschreibungen der Drohnentergite

\begin{tabular}{|c|c|c|c|}
\hline ARMBRLSTIER & ZANIDER & GOETZE & KUUIINČEVIĆ \\
\hline Bügel & $\begin{array}{l}\text { Vorderrandstreifen } \\
\text { mit beilformigen } \\
\text { Seitenflecken }\end{array}$ & Vorderrandspangen & $\begin{array}{l}\text { Vorderrandstreifen } \\
\text { mit Seitenffecken }\end{array}$ \\
\hline Sattel & $\begin{array}{l}\text { Mittelfeld mit } 2 \text { Sei- } \\
\text { tenrandbuchten }\end{array}$ & $\begin{array}{l}\text { Mittelstreifen } \\
\text { Rücken-Flanken u. } \\
\text { Lappen }\end{array}$ & $\begin{array}{l}\text { Mittelstreifen mit } \\
\text { Seiteneinsprüngen } \\
\text { Rücken-Flanken u. } \\
\text { Iappen }\end{array}$ \\
\hline (Sattel-)Bucht & $\begin{array}{l}\text { Hinterrand-oder } \\
\text { Mittelfeldbuchten }\end{array}$ & Buchten & Buchten \\
\hline Endmitte & $\begin{array}{c}\text { Rückenteil des Ilin- } \\
\text { terrandstreifens }\end{array}$ & $\begin{array}{l}\text { Hinterrandstreifen } \\
\text { Sattelstreifen }\end{array}$ & $\begin{array}{l}\text { Hinterrandstreifen } \\
\text { Sat telstreifen }\end{array}$ \\
\hline \multirow[t]{3}{*}{ Enclseiten } & $\begin{array}{l}\text { Seitenstreifen des } \\
\text { Hinterrandstrei- } \\
\text { fens }\end{array}$ & Seitenstreifen & Seitenstreifen \\
\hline & Inseln & Inselı & Inseln \\
\hline & & Spiegel & Spiegel \\
\hline
\end{tabular}


zen Pigments zur Folge. Die weitere Behandlung der Abdomina erfolgte in der gleichen Weise wie bei den feucht konservierten Tieren.

Für die nachfolgende Beurteilung und Klassifizierung der Zeichnungsmuster musste ich alle Abdomina in spezielle Vordrucke detailliert einzeichnen. Da bei der Pigmentierung und Musterbildung eine Asymmetrie selten ist, beschränkte ich mich auf die Zeichnung einer Tergithälfte. Dazu wählte ich die rechte Körperseite. Auf einen dem Drohnenhinterleib angepassten Glashaken schob ich die Abdomina so auf, dass dadurch alle Tergite gespreizt sehr gut sichtbar wurden. Die Verteilung von den unterschiedlich pigmentierten Flächen beurteilte ich mit Hilfe einer binokularen Lupe bei ${ }_{4}$-facher Vergrösserung.

\section{b) Erläuterung der Begriffe}

Die Beschreibung der Abdominal-Färbung setzt eine einheitliche Terminologie voraus. Die früheren Untersucher des Objektes Boveri (I915), ARMibruster (I923), ZANDER (1923), GoETzE (195I) stimmen in den Termini der verschiedenen Tergitbereiche nicht überein. In Tabelle 2 ver-
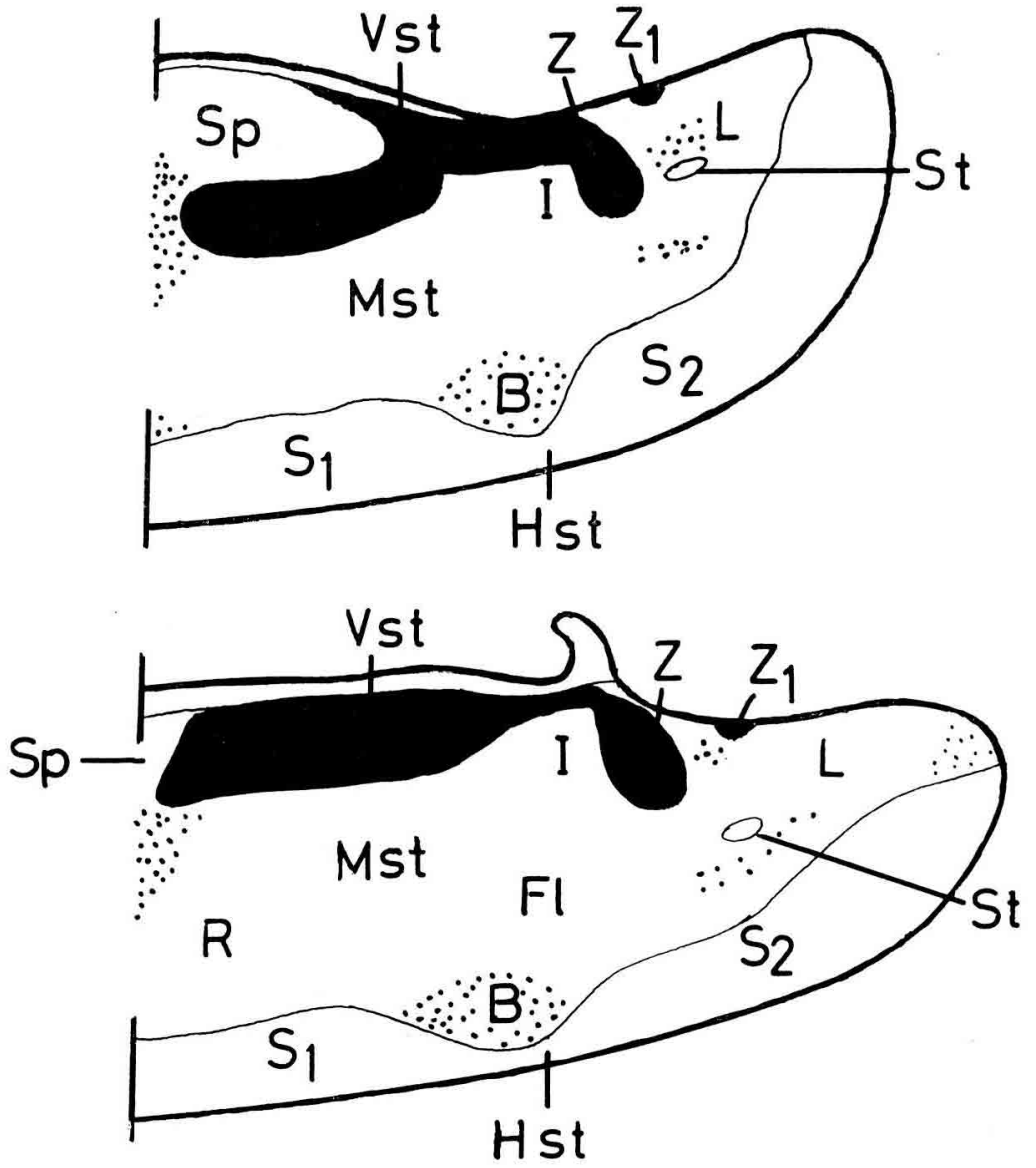

Aвв. 2. - 2. und 3. Tergit des Drohnen-Hinterleibes

FIG. 2. - 2e et $3^{e}$ tergites de l'abdomen du mâle

\footnotetext{
Vst $=$ Vorderrandstreifen

Mst $=$ Mittelstreifen

Hst $=$ Hinterrandstreifen

$\mathrm{S}_{1}=$ Sattelstreifen

$\mathrm{S}_{\mathbf{2}}=$ Seitenstreifen

$\mathrm{Z}^{2}=$ Seitenflecken

$Z_{1}=$ Seitenfleckchen
}

$$
\begin{aligned}
& \mathrm{R}=\text { Rücken } \\
& \mathrm{Fl}=\text { Flanken } \\
& \mathrm{L}=\text { Seitenlappen } \\
& \mathrm{B}=\text { Buchten } \\
& \mathrm{S} \mathrm{p}=\text { Spiegel } \\
& \mathrm{I}=\text { Inseln } \\
& \mathrm{St}=\text { Stigma }
\end{aligned}
$$


suchte ich, entsprechende Termini der verschiedenen Autoren einander zuzuordnen. GoETzE übernahm weitgehend die Begriffe von ZaNDER. Meine Terminologie entspricht zum Teil der von GoETzE (195I) benutzten, findet aber, bedingt durch die detailliertere Analyse, einige Abänderungen und Ergänzungen. So wird von mir der Ausdruck "Vorderrandstreifen " entsprechend der ZANDER 'schen Terminologie dem Ausdruck "Vorderrandspange " vorgezogen. Das von ZANDER als "beilförmige Seitenflecken " bezeichnete Zeichnungsmuster nenne ich "Seitenflecken " und halte als zusätzliches, benachbart liegendes Muster die "Seitenfleckchen "für eine Klassifizierung erforderlich. Die "Seitenrandbuchten " nenne ich "Seiteneinsprünge " um Verwechselungen mit den anderen "Buchten " zu vermeiden.

Abb. 2 vermittelt einen Eindruck von der räumlichen Zuordnung der Zeichnungsmuster auf dem II. und III. Drohnen-Tergit. Dabei ist vorauszuschicken, dass II. (und III.) Tergit in allen folgenden Ausführungen, wie es auch in den älteren Arbeiten gehalten wurde, bei den Drohnen entwicklungsmässig in Wirklichkeit das III. Tergit (SNODGRASS 1956) ist. Das I. Tergit gehört zum Propaedeum am Thorax-Abschnitt, und Tergit II bildet beim Drohn nur eine kleine Schale am Vorderende des Abdomens. Die Zählung erfolgt in meiner Arbeit und bei den älteren Autoren somit nur nach den zum Abdomen gehörenden Tergiten.

Während ZANDER (I921/23) das II., III., IV. und V. Tergit untersuchte, ARMbruster (I923) Tergit III, Goetze (I95I) Tergit II, III, IV, V und VI, RoberTs (I95I) das gesamte Abdomen und RUtTNER (1963) Tergit II, untersuchte ich Tergit II, III, IV und V. Nach meiner Meinung genügt das, um einen ausreichenden Eindruck von der Pigmentverteilung und Musterbildung des Hinterleibes zu erhalten. Die genaueste Analyse erfolgte an Tergit II.

\section{c) Aufstellung des Klassensystems}

Die Färbung des Drohnenabdomens stellt die Resultante von fünf Einzelkomponenten dar :

I. Die Pigmentfarben unterschiedlichen chemischen Aufbaues. Soweit bisher bekannt, gehören die gelben Pigmente den Flavonen, die schwarzen den Melaninen an.

2. Die Pigmentdichte, die den Farbton bestimmt. ist.

3. Die Mischung der beiden Pigmentkomponenten, die ebenfalls von Einfluss auf den Farbton

4. Das Zeichnungsmuster, d.h. die geordnete räumliche Verteilung der Pigmente über die Tergit-Fläche.

5. Die Feinstruktur der chitinösen Trägersubstanz, die spezielle Oberflächeneffekte hervorruft.

Die bei den Arbeiterinnen für den farblichen Gesamteindruck so entscheidende Behaarung fällt bei den Abdomina der Drohnen nicht ins Gewicht.

In der vorliegenden Arbeit wurde primär die Ausgestaltung der dunklen Muster auf dem gelben Untergrund der Tergite untersucht. Die Zeichnungen der mehr als I ooo Exemplare verschiedener geographischer Herkunft wurden so angeordnet, dass eine kontinuierliche Reihe in der Ausbreitung des dunklen Farbmusters über die Abdominal-Tergite entstand (Abb. 3). Nach meiner Ansicht ist für die Rassengruppe, die die Apis mell.carnica, A. mell. mellifica, A. mell. lamarckii - Fasciata, A. mell. armenica, A. mell. meda - Persica und A. mell. intermissa-Sahariensis umfasst, eine ro-klassige Einteilung angemessen. Für die Apis mellifica ligustica war ein eigenes System erforderlich, das in der Beschreibung noch gerechtfertigt wird.

\section{Allgemeines Schema der 10 Klassen \\ der untersuchten Drohnen-Tergite verschiedener geographischer Rassen von Apis mellifica $L$.}

Klasse A-I : Der Mittelstreifen des 2. T. ist gelb, der Spiegel breit geöffnet. Die Vorderrandstreifen des 3. T. sind nur mit dünnem Pigment versehen, aber zumeist noch nicht verbunden. Im übrigen ist der ganze Mittelstreifen melaninfrei. Das 4. T. ist mit Melanin schon stärker bedeckt, und der kleine Spiegel ist breit. Die Seiteneinsprünge sind tief. Das 5. T. ist dem 4. ähnlich. Auch hier finden wir Spiegel und offene Seiteneinsprünge gelb pigmentiert.

Klasse A-II : Das 2. T. ist dem der Klasse I ähnlich, nur der dunkle Rand des Spiegels ist dunkler pigmentiert aber weiter geöffnet. Das 3. T. ist schon durch die Pigmentierung der SpiegelUmrandung ganz verschlossen. Sehr selten geht die Pigmentierung jedoch weiter zum Sattelstreifen. Bei einigen Rassen (Fasciata, Sahariensis und Cypria) verläuft die Pigmentierung umgekehrt, d.h. der kleine Spiegel bleibt offen, die Buchten enthalten schon Pigment und entlang des Sattelstreifens sind die Buchten schon verbunden. Der Mittelstreifen ist zum Teil mit einem gelben Ring zu vergleichen. Das 4. T. hat einen kleinen gelben Spiegel, ziemlich tiefe gelbe Seiteneinsprünge 


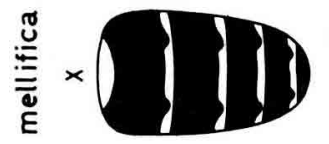

g

ชั$$
\text { : }
$$

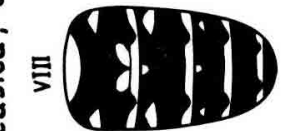

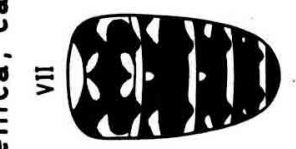

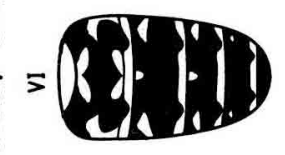

ता का

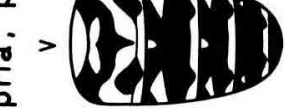

๙ิ

${\underset{\pi}{0}}_{i}^{\infty} \geq\left\{\begin{array}{lll}r & 1\end{array}\right.$

๘

i लिएक

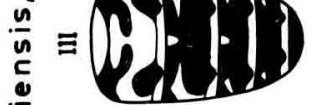

䍃

in

$=$

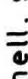

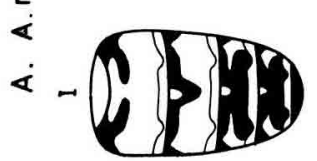
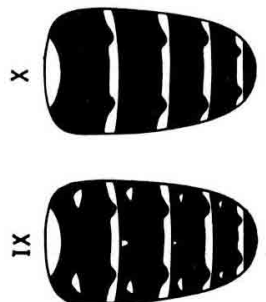

$\left.\left.\equiv \int_{1}^{1}\right\}_{1}^{1}\right\}$

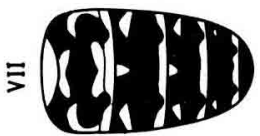

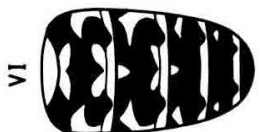

$>$ Baria

$\geq B$ bis:

$\equiv 0\}\left\{\begin{array}{l}5 \\ 0\end{array}\right\}$

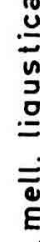

$\stackrel{\dot{c}}{\infty}-5\}\{3$ $\times 9$

$\times \int_{1}^{1}, 1$

$\equiv \int_{a}^{0} y^{1} \cdot 1$

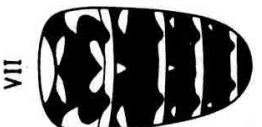

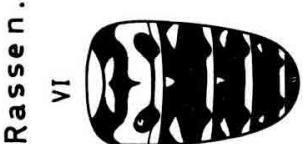

용

ह

- 氞

온

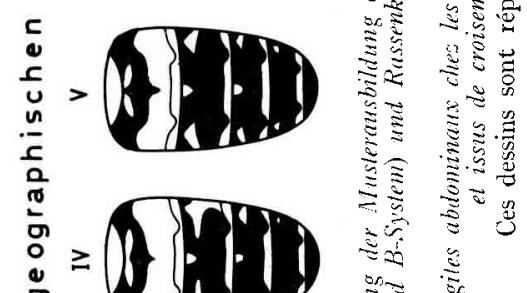


und der Mittelstreifen ist verdunkelt. Das 5. T. enthält einen sehr stark verkleinerten Spiegel und in sich geschlossene gelbe Inseln. Die Seitenflanken sind auch mehr oder weniger stark pigmentiert.

Klasse A-III : Der Spiegel des 2. T. ist noch offen, aber die Buchten sind mit Pigment besetzt. Das 3. T. hat Seiteneinsprünge, die melaninfrei sind und der kleine Spiegel ist ebenfalls gelb. Die Seitenflanken enthalten keine Spuren von Melanin. Der Mittelstreifen ist verdunkelt. Das 4. T. enthält noch kleine gelbe Spiegel und Seiteneinsprünge, aber die Ausdehnung des Pigments greift jetzt immer weiter von den Buchten zu den Flanken über. Das 5. T. enthält nur noch gelbe Inselchen, ansonsten ist es ganz pigmentiert.

Klasse A-IV : Die Spiegelumrandung des 2. T. ist jetzt geschlossen, da beide Vorderrandstreifen in der Medianlinie völlig aneinanderstossen. Der Mittelstreifen ist gelb und die Buchten enthalten kein Pigment. Der Mittelstreifen des 3. T. ist ausser Seiteneinsprünge und kleinen Spiegeln verdunkelt. Die Seitenflanken sind pigmentfrei. Das 4. T. hat noch gelbe, verkleinerte Spiegel und schmale Seiteneinsprünge, die kein Melanin enthalten. Das 5. T. ist ausser den sehr kleinen gelben Inseln dunkel pigmentiert.

Klasse $A-V$ : Die Pigmentierung am Rande des geschlossenen Spiegels beim 2. T. verläuft caudal in spitzer Form in Richtung des Sattelstreifens. Eine andere Spitze entwickelt sich entgegengesetzt und drängt in die Mitte des Spiegels. Die Buchtenflächen sind stark ausgebildet, aber noch nicht mit dem Vorderrandstreifen verbunden. Ein Teil des Mittelstreifens zeigt noch seine gelbe Farbe. Das 3. und 4. T. haben noch gelbe Seiteneinsprünge und kleine Spiegel. Das 5. T. ist verdunkelt und enthält noch sehr kleine gelbe Inseln.

Klasse A-VI: Hier ist der Spiegel des 2. T. noch kleiner geworden. Die Melanineinlagerung in Richtung des Sattelstreifens ist herzförmig ausgebildet und erreicht diesen bereits. Die entgegengesetzte, frontal gerichtete Spitze (siehe Klasse V.) hat die Mitte des Spiegels überschritten. Die Buchtenflächen sind durch Melaninausdehnung mit dem Vorderrandstreifen verbunden. In den Mittelstreifen sind noch gelbe Flächen entlang dem Sattelstreifen eingelagert. Die Seitenflanken sind gelb. Manchmal kommt auch eine Pigmentausweitung von den Seitenflächen in die Seitenlappen vor. Das 3. T. ist dunkel pigmentiert und hat schmale gelbe Seiteneinsprünge und kleine Spiegel. Das 4. ähnelt dem 3.. Das 5. T. enthält nur kleine, gelbe Inselchen.

Klasse $A-V I I$ : Die Spitze von dunklem Pigment hat den Spiegel des 2 . T. in 2 Teile geteilt. An den Flanken schreitet die Ausdehnung des Melanins weiter fort, doch sind die Seiteneinsprünge noch breit und melaninfrei. Die gelbe Fläche entlang dem Sattelstreifen ist kleiner geworden und bei einigen Rassen existiert diese bereits nicht mehr. Das 3., 4. und 5. Tergit entsprechen denen der Klasse VI.

Klasse A-VIII : Der Spiegel des 2. T. ist völlig melanisiert. Die gelben Seiteneinsprünge sind, kleiner und enger geworden. Die dunkle Pigmentierung ist noch weiter in die Seitenflanke vorgedrungen und die gelbe Fläche entlang des Sattelstreifens annähernd verschwunden. Das 3. T. hat noch gelbe, melaninfreie, kleine Spiegel und sehr kleine Seiteneinsprünge. Das 4 . T. enthält einen melaninfreien kleinen Spiegel und kleine Inseln. Das 5. T. ist ganz verdunkelt.

Klasse A-IX: Das 2., 3. und 4. T. enthalten noch melaninfreie Inseln. Das 5. T. ist vollständig melanisiert.

Klasse A-X : Alle Tergite, bzw. Mittelstreifen des Hinterleibes sind vollständig vom Melanin eingenommen und ohne gelbe Zeichen.

Diese Klassen sollen für die Mehrzahl der in dieser Arbeit behandelten geographischen Rassen der Art Apis mellifica L. gelten. Natürlich kann das nur ein willkürlich durch die Vorstellung des Untersuchers gesetzter Rahmen sein. In der Einzelanalyse der Rassen werde ich nur noch Besonderheiten und kleinere Unterschiede der verschiedenen Rassen unterstreichen.

\section{Schema der 10 Klassen der untersuchten Drohnen-Tergite der geographischen Rasse A. mellifica ligustica SPIN 1808}

Klasse B-I : Die Mittelstreifen des 2. und 3. T. sind gelb. Der Spiegel des 2. T. ist breit geöffnet. Der Mittelstreifen des 4 . T. ist auch gelb, jedoch findet man bei manchen Drohnen die Mitte der Vorderrandstreifen mit dünnem Pigment verbunden. Der Mittelstreifen des 5. T. ist schon pigmentiert, doch haben wir entlang dem Sattelstreifen ellipsenförmige Aufhellungen. Die Seiteneinsprünge sind tief und melaninfrei, und der kleine Spiegel dieses Tergites ist relativ breit.

Klasse B-II: Die Mittelstreifen des 2. und 3. T. sind melaninfrei. Der dunkle Rand des Spiegels beim 2. T. ist stärker melanisiert und der gelbe Durchbruch in der Medianlinie enger geworden, 
aber noch nicht geschlossen. Den Mittelstreifen des 4. T. bedeckt bereits Melanin. Auch hier finden wir die gelben, ellipsenförmigen Ausbuchtungen in frontaler Richtung entlang dem Sattelstreifen, dazu gelbe Seiteneinsprünge. Dieses Tergit enthält ebenfalls einen etwas grösseren Spiegel. Das 5. T. ist dem 4. 'l'. analog, nur ist hier die Melanisierung stärker ausgebildet.

Klasse $B \cdot I I I$ : Der Mittelstreifen des 2. T. ist melaninfrei, die Spiegelumrandung aber jetzt geschlossen. Der Mittelstreifen des 3. T. ist ebenfalls fast melaninfrei. Nur bei einigen Drohnen finden wir dort cine dünne Melanisierung, wo die Vorderrandstreifen einen kleinen Spiegel ausbilden. Der Mittelstreifen des 4. T. ist schon melanisiert, aber die ellipsenförmigen Flächen und Seiteneinsprünge sind noch melaninfrei. Das 5. 'T. ist sehr stark pigmentiert, nur die ganz kleinen Spiegel und die engen Seiteneinsprünge sind noch gelb geblieben. Die Melanisierung entlang der SeitenSattelstreifen ist in die Seitenflanken verlängert.

Klasse $B-I V^{\prime}$ : Der Spiegel des 2. T. ist geschlossen, aber die jetzt zusammenhängenden Vorderrandstreifen haben median zwei melanisierte Spitzen ausgebildet. Eine Spitze verläuft frontal, die andere caudal. Der Mittelstreifen ist noch gelb. Beim 3. 'T. haben wir schon im Bereich des Mittelstreifens und teilweise in den Buchten gut erkennbare Melanisierung. Der kleine Spiegel ist von Melanin umrandet. Die ellipsenförmigen, melaninfreien Flächen sind gross, und die Seiteneinsprünge reichen fast bis zur Mitte des Tergites. Der Mittelstreifen des 4. T. ist nahezu verdunkelt, dabei sind nur der kleine Spiegel und die Seiteneinsprünge melaninfrei. Der Mittelstreifen des 5. T. ist bis auf die Inselchen völlig melanisiert.

Klasse B-I : Der Unterschied zwischen der V. und VI. Klasse besteht nur darin, dass die Buchten des 2. T. vollkommen melanisiert sind.

Klasse B-VI : Der Spiegel des 2. T. ist viel kleiner geworden. Die Melaninspitzen in beiden Richtungen sind stärker ausgebildet. Die Buchtenflächen haben sich durch die Verlängerung der Vorderrandstreifen vereinigt. Damit ist die gelbe Fläche des Mittelstreifens unterbrochen. Der Mittelstreifen des 3. T. ist melanisiert. Ellipsenförmige kleine Flächen und tiefe Seiteneinsprünge, sowie der kleine Spiegel sind melaninfrei. Das 4. T'. ist verdunkelt, nur die etwas grösseren Inselchen und der kleine Spiegel verbleiben gelb. Die Melanineinlagerung des Mittelstreifens zieht sich bis zu den seitenflanken. Der Mittelstreifen des 5. T. ist bis auf kleine Inselchen völlig melanisiert.

Klasse B-VII : Der Spiegel des 2. T. ist weiter verkleinert aber median noch nicht unterbrochen. Die gelbe Fläche des Mittelstreifens ist noch gut sichtbar. Der Mittelstreifen des 3. ' $\mathrm{I}$ '. ist melanisiert. Die Seiteneinsprünge sowie der kleine Spiegel sind melaninfrei. Das 4. T. ist verdunkeit. Nur die Inseln und der kleine Spiegel sind noch gelb. Der Mittelstreifen des 5. T. ist auch verdunkelt. Als einzige melaninfreie Flächen sind die kleinen Inseln verblieben.

Klasse B-I III : Der Spiegel des 2. T. ist frontal zusammengedrängt aber noch nicht median unterbrochen. Die gelbe Fläche entlang dem Sattelstreifen ist noch vorhanden. Gelbe Inseln finden wir in Tergit 2-5. Melaninfreie kleine Spiegel sind im 3. und 4. T. nachweisbar.

Klasse B-IX: Alle untersuchten Tergite (2., 3., 4. und 5.) enthalten melaninfreie Inseln. Das 3. und 4. T. besitzen kleine Spiegel.

In diesem System bilden die Klassen B-I, B-II und B-III ein Charakteristikum ; das ist besonders bei B-III klar sichtbar. Diese Klasse hat zwei gelbe Tergite, aber einen geschlossenen Spiegel iin 2. Tergit. Beim A-System kommt dieser geschlossene Spiegel nur bei Klassen mit einem gelben Ring vor. Eine Einordnung dieser Klasse in das A-System würde eine Unterbrechung des Systems verursachen. In diesem Fall wäre jede graph. Darstellung in zwei Teile geteilt - solche Kurven hätten keinen Wert.

Die Klassen B-I und B-II sind bedeutend weniger melanisiert als entsprechende in A-System ; gewisse Unterschiede im Zeichnungsmuster bestehen.

Die Klassen B-IV bis B-VI sind in ähnlicher Form im A-System vorhanden. Sie unterscheiden sich vom A-System durch ellipsenförmige helle Flächen entlang des Sattelstreifens des 2. Tergits. Die Exemplare der Klassen B-VII, B-VIII und B-IX fand ich noch zum Schluss in einer Drohnenprobe von einer Tochterkönigin einer von Norditalien importierten, begatteten Königin. Die Verteilung der Zeichnungsmuster bei diesem Material war nicht eingipfelig, sondern mit zwei Maxima und einem Minimum, was deutlich zeigte, dass diese Drohnen wahrscheinlich durch eine Kreuzung zwischen einer hellen und einer dunkleren Form entstanden sind. Vollständig melanisierte Formen lagen aber auch in diesem Material nicht vor. GOETZE (I95I) beschrieb noch dunkleres Material. Nach Angaben von Gravarini (1953) soll sich diese Klasse (Klasse B-X) bei der A. mell.lig. in Italien finden.

Wie stark die Aufstellung der Klassifizierung von der persönlichen Vorstellung des Untersu- 
chers abhängig ist, ergibt sich aus einem Vergleich der Klassensysteme. ZANDER (I92 I) stellte eiue Klassifizierung von $\mathrm{M}_{0}$ bis $\mathrm{M}_{11}$ auf und ordnete seine Cypria, Mellifica und andere Stufen in diese Klassen ein. Armbruster (1923) bevorzugte bei der Analyse der Musterbildung auf dem 3. Tergit von Biene und Drohn ein System mit 9 Klassen. Goztze (I930, 195I) legte für Bienen ein neunklassiges und für Drohnen ein sechsklassiges zu Grunde. Bei RoBERTs (I950) finden wir für Arbeiterinnen I3 Klassen, RUTtNeR (1962) ordnet seine Zeichnungsmuster von Bienen von I-9 an.

\section{II. - Befunde der Proben verschiedener geographischer Herkunft :}

a) Geographische Rasse A. m. intermissa BUT.-REEP. I906 - Sahariensis

Am Anfang unseres Jahrhunderts fand BALDENSPERgER diese Biene am Rande der Sahara und gab ihr (I933) nach einer ausführlichen Beschreibung den Namen Sahariensis (Saharienne). Nach BALDENSPERGERS Beobachtung ist die gelbe $A$. m. intormissa Form am Rande der Sahara in Oasen und die schwarze Form der A. m. intermissa längs des Mittelmeeres häufiger. Weiter erwähnt er, dass diese nordafrikanische Apis von hell bis dunkel variiert, und dennoch halten sich die Rassen-Farb-Varietäten wegen der natürlichen Hindernisse gut getrennt.

Al,BER (I952) fand in den besuchten Oasen von Tunesien and Algerien nur dunkle Bienen und er sagt, er werde den Verdacht nicht los, dass BALDENSPERGERS Saharabienen am Ende nur Italienernachzuchten waren.

TeMPLER (I957) hat die Bienen der Kanarischen Inseln beschrieben und fand, dass sie den Saharabienen ähnlich sind. Ein Einfluss seitens der Ligustica wird von TEMPLER als unwahrscheinlich angenommen. Die heutigen kanarischen Bienen sollen im I4. Jahrhundert aus Nord-Afrika von Guanchen eingeführt worden sein. In letzter Zeit hat HAccour (I960, I962) durch persönliches Engagement im Bienenhandel die Sahariensis ziemlich bekannt gemacht, und er fand sie - entsprechend der Beschreibung BALDENSPERGERS (I933) - im Tal von Souss.

Bruder Adam (1964) war in Marokko auf der Suche nach neuen Bienenrassen und stellte Vergleiche zwischen Sahariensis und anderen Rassen an.

GOETZE (I964) befasste sich mit der Sahariensis und schildert, dass ihre Drohnen typische Farbmuster entwickelten, die mit denen der Ligustica nicht übereinstimmen.

Von den Drohnenproben, die ich hier für Musterbildungs- bzw. SattelfigurenBestimmung benutzte, stammen zwei $\left(S_{1}\right.$ und $\left.S_{3}\right)$ von Originalvölkern aus Marokko, die von Haccour 1962 nach Deutschland geschickt wurden. $S_{2}$ und $S_{4}$ sind Nachzuchten von $S_{1}$ und $S_{3}$, die man im Bonner Institut für Bienenkunde erhalten hat.

Im oberen Abschnitt von Abb. 4 sind alle Drohnenproben von mir in einer graphischen Darstellung zunächst analytisch zusammengestellt.

Die Sattelfiguren bei der Sahariensis-Probe $S_{1}$ erstrecken sich von Klasse A-III bis A-IX mit dem Maximum in A-VII.

Die Probe $\mathrm{S}_{2}$ umfasst 4 Klassen, von $\mathrm{A}-\mathrm{V}$ bis $\mathrm{A}$-VIII. Das Maximum besteht in Klasse VII wie bei $S_{1}$. Fin zweites, etwas geringeres Maximum finden wir in Klasse A-V.

Sahariensis-Probe $S_{3}$ findet sich zwischen Klasse A-III und A-X. Die Klassen A-IV und A-VIII waren in dieser Probe trotz grosser Drohnen-Anzah1 nicht enthalten. Auffallend ist das grosse Maximum in Klasse A-V, ungewöhnlich der Anteil in Klasse IX und X. Diese Klassen sind ganz dunkel, was für die Sahariensis-Biene nicht charakteristisch sein sol1. Diese Erscheinung kann ihren Ursprung in möglichen früheren Kreuzungen haben. 
Die Probe $S_{4}$ geht von A-IV bis A-X. Ihr Maximum liegt bei A-VI, aber A-VII und A-VIII zeigen ähnliche Werte. Die Klasse A-IX fehlt.

Einen Gesamteindruck über die Klassenverteilung aller Sahariensis-Proben synthetisch zusammengefasst erhalten wir aus der Kurve im unteren Teil von Abb. 4 . Wir sehen, dass sich die Sahariensis von Klasse A-II bis A-X erstreckt. Im Bereich der Klassen A-III und A-IV befinden sich weniger als $5 \%$ Drohnen-Anteil. Das Maximum ist in der Klasse A-V. Vom Maximum fällt die Kurve bis zur Klasse A-IX stufenförmig ab. Von hier steigt sie wieder bis zu einem Nebengipfel in Klasse A-X an.

Wenn wir die Klassen mit weniger als $5 \%$ Anteil ausschliesssen, finden wir die Sahariensis zwischen den Klassen A-V und A-X. Dies zeigt uns das vergleichende Diagramm in Abb. II.

Charakteristisch für die Sahariensis ist, dass bei ihr wie bei der Fasciata und Cypria kleine, sehr stark pigmentierte Seitenfleckchen vorliegen. Diese Fleckchen sind unabhängig ausgebildet von anderen Pigmentierungs-Ausgangspunkten. Die Seitenflanken-Pigmentierung kommt als Verlängerung der Mittelstreifen-Pigmentierung und sehr selten neben den Stigmen vor. Die Buchten sind primäre Ausgangspunkte für Melanisierung. Beim 3. Tergit kommen immer beide Buchten mit Melanisierung dicht neben dem Sattelstreifen vor. Von hier verläuft die Melanisierung in Richtung des geöffneten Spiegelchens.

\section{b) Geographische Rasse A. m. lamarckii COCKERELL I906 (Synonym : Fasciata (1))}

Diese Bienen finden sich im Niltal und zahlreichen Oasen Ägyptens. Sie sind klein und gehören zu der Gruppe der gelben Bienen. Das Chitin der Drohnen ist leuchtend orange-farben (ROTTER, I9I9).

Von BUTTEL-REEPEN (Ig06, I9I5, I92I) hat sie als var. fasciata in Subspecies unicolor der Art Apis mellifica L. aufgefasst. Er und ZANDER (I923) glauben, dass die sog. "goldene Biene ", eine Zuchtform mit hervorstechender gelber Pigmentierung, zu Beginn dieses Jahrhunderts durch Kreuzung mit der Fasciata entstanden sei.

GoeTze (I938) ist der Meinung : “... auf jeden Fall bestehen enge Beziehungen zwischen der Fasciata und den übrigen Rassen des Orients wie Cypria, Syriaca, Meda usw. ". Er bezweifelt, dass die Fasciata zur afrikanischen Rasse Unicolor gehört, WERTheim (I940) dagegen rechnet sie dazu. Hassanein und Ei Banby (I956), KASchEF (I959), KERR (I958), SMITH (I96r) und Ei, BANBY (I963) beschäftigen sich mit dieser Bienenrasse unter morphologischen und systematischen Gesichtspunkten.

Bruder ADAM (I964) hat über die Fasciata während seines Aufenthaltes in Ägypten einige Bemerkungen gemacht. Er sagte : "Aus einem noch unbekannten Grunde lässt sich die Fasciata-Königin in ihrer natürlichen Umgebung nicht mit Drohnen anderer Rassen kreuzen. " Aus diesem Grunde findet man in Ägypten noch reinrassige Fasciata trotz grosser Einfuhr von europäischen Bienen. Bruder ADAM ist der Auffassung, dass die Fasciata als genetisches Material von Bedeutung ist, obwohl sie in reiner Form für die Bienenwirtschaft ungeeignet erscheint. I964 ordnete GOETZE die Fasciata als geographische Rasse der Subspecies Meda ein.

In meiner Analyse wurden drei Drohnen-Proben erfasst. Wie aus der Übersicht

(1) In dieser Arbeit wird das Synonym Fasciata benutzt, weil es in der Literatur sehr häufig u. inı der Praxis der gebräuchliche Name ist. 

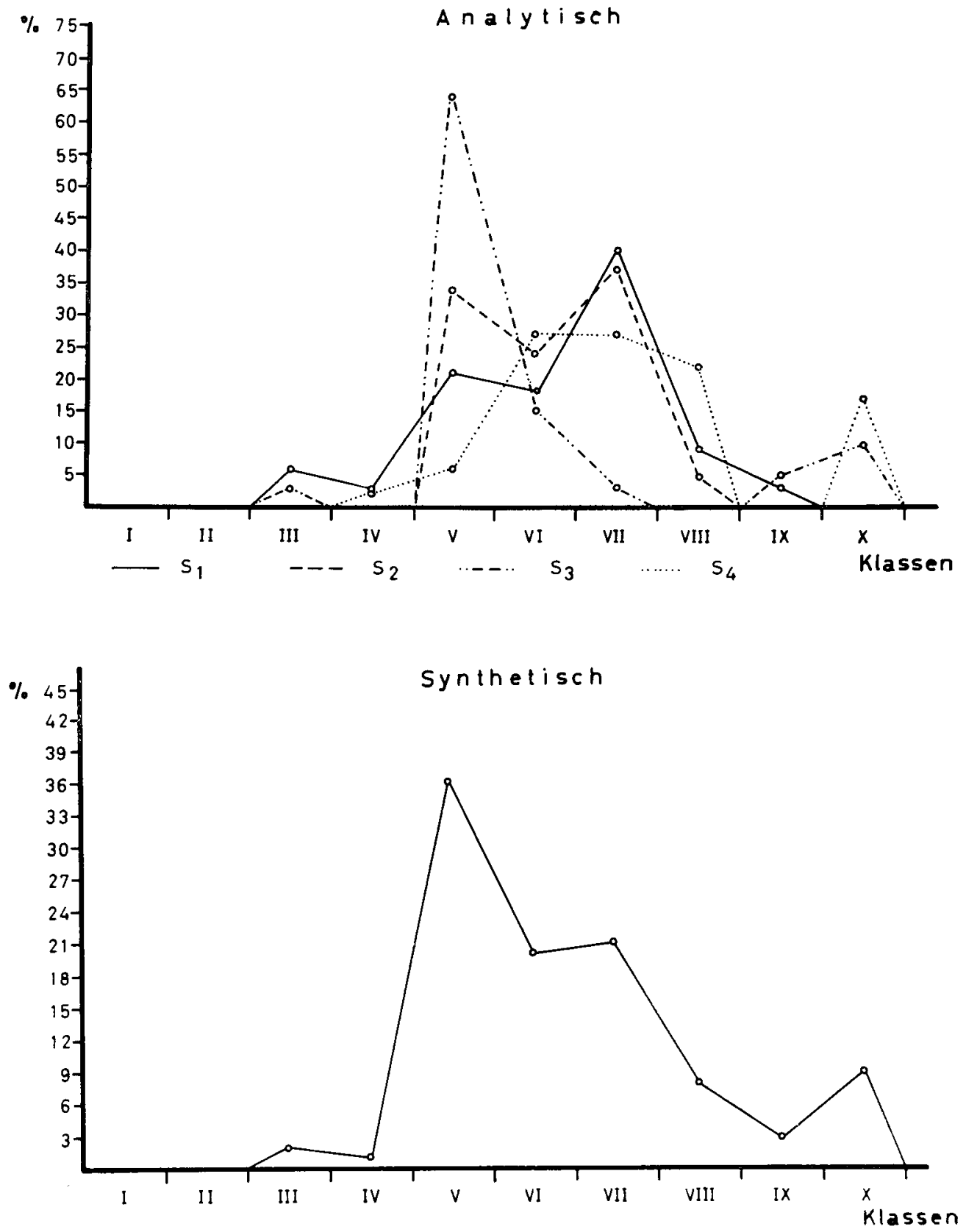

ABв. 4. - Graphische Darstellung (analytisch und synthetisch) sur Verteilung von 4 Proben der Sahariensis-Drohnen im A-Klassensystem

FIG. 4. - Répartition de 4 séries de mâles de la race Sahariensis dans le système $A$ 
Abb. I ersichtlich ist, sind zwei Proben $\left(F_{1}\right.$ und $\left.F_{2}\right)$ aus Ägypten, $F_{3}$ wurde der Sammlung des Bonner Institutes entnommen.

Auch hier haben wir eine analytische Darstellung (Abb. 5). Bei $F_{1}$ habe ich die Sattelfiguren der Klasse A-II bis A-VIII festgestellt. Das Maximum der DrohnenSattel-Figuren befindet sich in der Klasse A-III. Nur eine Drohne gehört der Klasse $\mathrm{A}-\mathrm{X}$ an. Sie war das einzige ganz melanisierte Exemplar in der Fasciata-Gruppe.

Die $\mathrm{F}_{2}$ erstreckt sich von Klasse A-III bis A-VIII. Hier liegt das Maximum in der Klasse A-VI.

Die Probe $F_{3}$ geht von Klasse A-II bis A-VIII. Die Klassen A-IV und A-VI fehlen. Das Maximum befindet sich in der Klasse A-V und ist ausgesprochen hoch. Isolierte Gruppen dieser Probe befinden sich in den Klassen A-II und A-III, sowie in A-VII and A-VIII.

Bei allen Proben herrscht die Tendenz zum zentral gelegenen Maximum vor. Dieses wird besonders deutlich in der synthetischen Darstellung in Abb. 5. Hier liegt das Maximum in der Klasse A-V und die Kurve fällt beidseitig des Hochpunktes, zum Teil in Stufenform, ab. Der Klassenanteil tiber $5 \%$ erstreckt sich von der Klasse A-III bis zu A-VIII, dargestellt im Diagramm Abb. II.

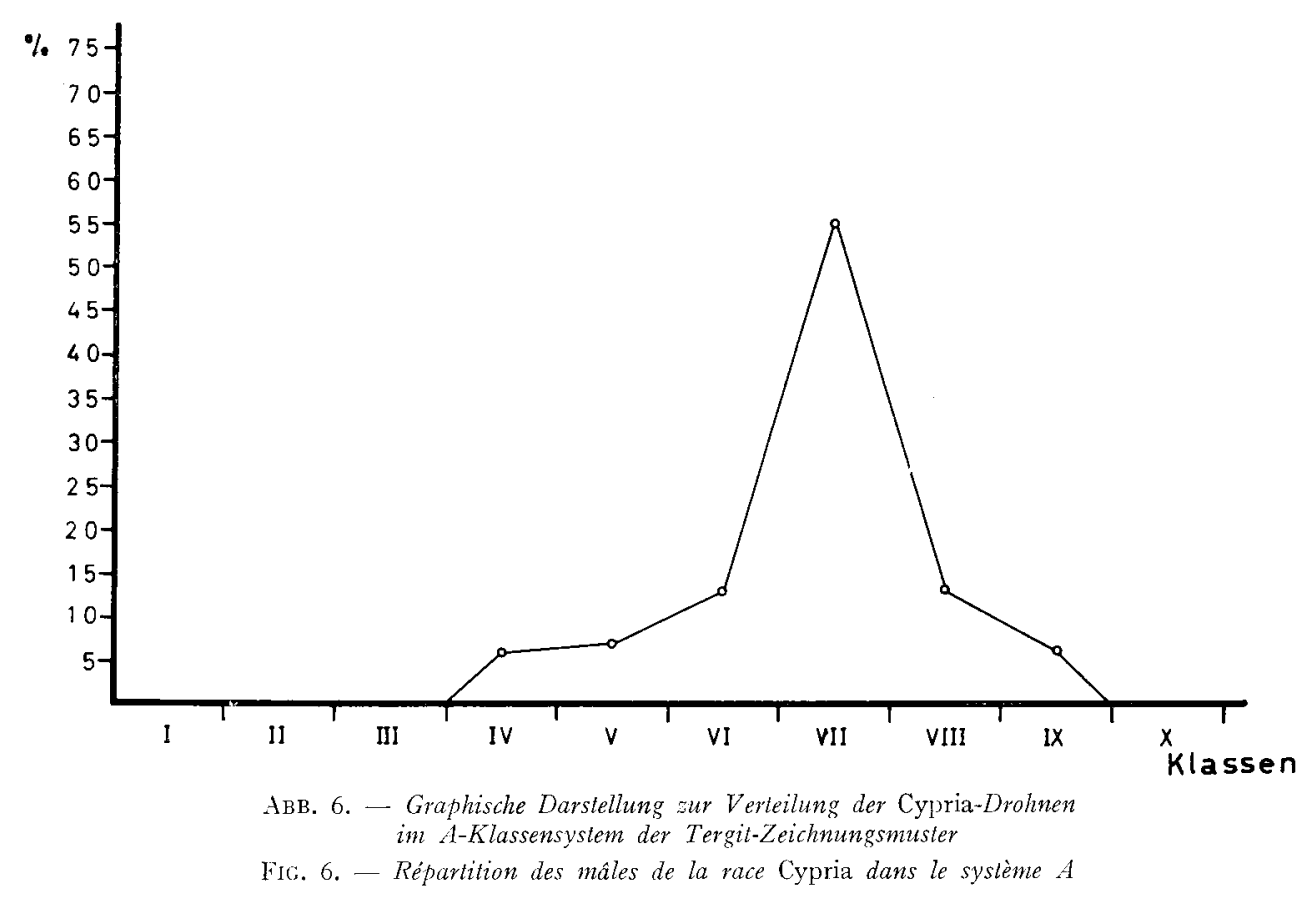

Die Musterbildung bei dieser geographischen Rasse hat einige Besonderheiten. Die Seiten-Flanken und die Seiten-Lappen bewahren trotz fortschreitender Melanisierung der zentralen Bereiche verhältnismässig lange ihre helle Pigmentierung. Die Melanisierung neben den Stigmen ist nicht unabhängig. Sie tritt immer als Verlängerung des Mittelstreifens, bzw. der Buchten auf. Relativ oft finden wir stark pigmentierte kleine Fleckchen neben den Seitenflecken. Diese Fleckchen kommen 
sowoh1 bei den hellen Klassen A-II, A-III usw., als auch bei dunkleren Klassen A-VII und A-VIII vor. Das Zeichnungsmuster des 3. Tergites gleicht dem von Sahariensis.

c) Geographische Rasse A. m. cypria PoLLM. I879

Bei der Cypria handelt es sich um eine geographische Bienenrasse, die auf einer Insel (Cypern) bodenständig ist. Von BuTTEL-REEPEN (Igo6, Igr5) stuft die Cypria als Varietät der Subspecies Mellifica ein und trennt, wie wir bereits sahen, die Cypria von der Fasciata.

GOETZE (I964) ordnete die Cypria als geographische Rasse der Subspecies Meda ein.

Die einzige Drohnen-Probe $C_{1}$, die in der Sammlung des Bonner Institutes vorhanden war, erstreckt sich über die Klassen A-IV bis A-IX (Abb. 6). Das Maximum dieser Rasse liegt in der Klasse A-VII. Die absteigende Kurve ist nahezu symmetrisch. Auch hier haben wir sechs Klassen mit über $5 \%$, wie aus dem Diagramm Abb. I4 ersichtlich ist.

Die Pigmentierung zeigt keine nennenswerten Unterschiede zur Fasciata und Sahariensis. Auch hier finden sich kleine unabhängige Seitenfleckchen, ein Charakteristikum für das Tergit-Zeichnungsmuster bei den Drohnen der vorgenannten drei Rassen.

\section{d) Geographische Rasse A. m. meda sKorikow I929, Persica (1)}

Die systematische Zugehörigkeit der Bienen aus dem persischen und afghanischen Raum ist heute noch weitgehend ungeklärt. In einer geographischen Karte über die Verbreitung der Honigbienenrassen von GoE'TzE (I938) finden sich keine Eintragungen in diesem geographischen Bereich. Die Situation ist bis heute unverändert geblieben. So schrieb Bruder ADAM I965: "Wir wissen so gut wie nichts über die einheimischen Bienen im Iran und Afghanistan. "

SkorIkow (I929) klassifizierte die Bienen aus Persien in seiner Bienen-Systematik als $A$. mell. meda.

Drei kleine Proben (zwei zu je fünf Drohnen und eine mit II Stück) erhielt ich aus diesem Raum. Wegen der geringen Anzahl ist ein vollständiges Bild über die Pigmentierung und Musterbildung dieser unbekannten Bienen kaum möglich. Ich möchte jedoch versuchen, an Hand dieser Proben Rückschlüsse zu ziehen.

Alle drei Proben $P_{1}, P_{2}$ und $P_{3}$ ordnen sich in das Klassensystem von A-I bis $A-X$ ein (Abb. 7). In ihrer Gesamtheit betrachtet ergeben diese Proben eine fast lückenlose Verteilung der Drohnenpigmentierung über alle Io Klassen. Das bedeutet, dass sich in Persien neben zweiringig gelben Drohnen im Süden auch ganz dunkle Drohnen im Norden finden. Bei den persischen Drohnen liegen keine kleinen Seitenflecken vor wie bei der Sahariensis, Cypria und Fasciata.

(1) Wegen der Unklarheit über die systematische Stellung habe ich den Arbeitsnamen Persica benutzt. Das schliesst jedoch nicht ein, dass die Bienen aus Persien eine klar umrissene geographische Rasse darstellen mütssen. 

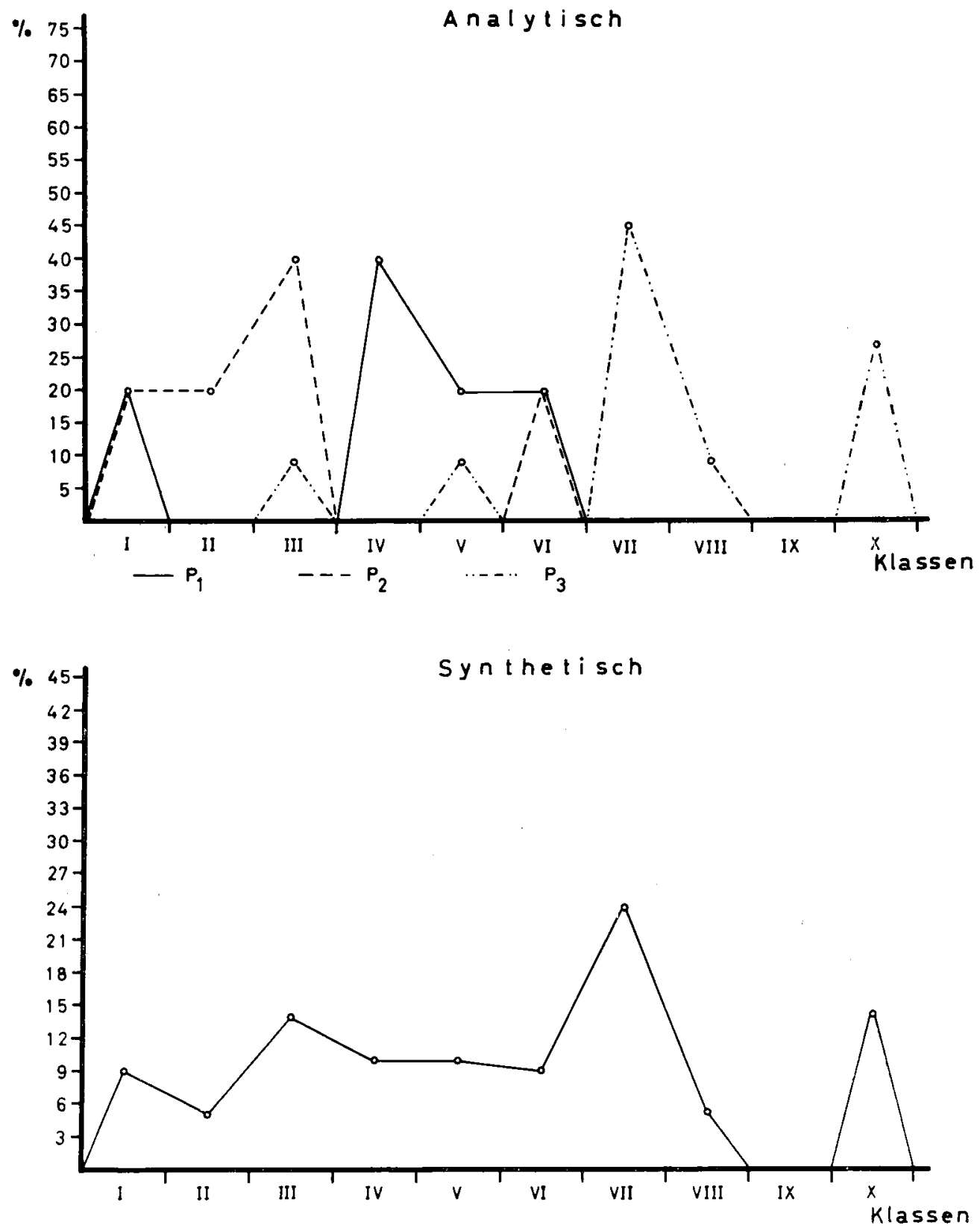

AвB. 7. - Graphische Darslellung (analytisch und synthetisch) zur Aufgliederung ler 3 persischen Drohnenproben im A-Klassensystem

FIG. 7. - Répartilion des mâles de la race Persica dans le systène $A$ 
e) Geographische Rasse A. m. armenica sKORIKOW Ig29

SkorIKow (1930) stellte im Kaukasus einige nach seiner Auffassung neue Bienenarten fest. Dieses können aber nur geographische Rassen sein. Unter den neuen Funden war die Rasse Armenica.

Nach MARKosJan (I960) gibt es in Armenien eine hellgelbe und eine graue Bienenrasse.

KatogJan (1963) schildert auch zwei "Arten " von armenischen Bienen : graue aus den Bergen und gelbe aus den Tälern.

Eine Probe von diesen Drohnen habe ich aus Russland erhalten. Ich stellte bei dieser Armenica-Probe Sattelfiguren in den Klassen A-IX und A-X (Abb. 8) fest. Das heisst, die überwiegend dunklen Sattelfiguren-Klassen, die mehr als $5 \%$ des Gesamtanteils ausmachen, beginnen in A-VII ; sie erscheinen im Diagramm Abb. II an 5. Stelle nach der Sahariensis.

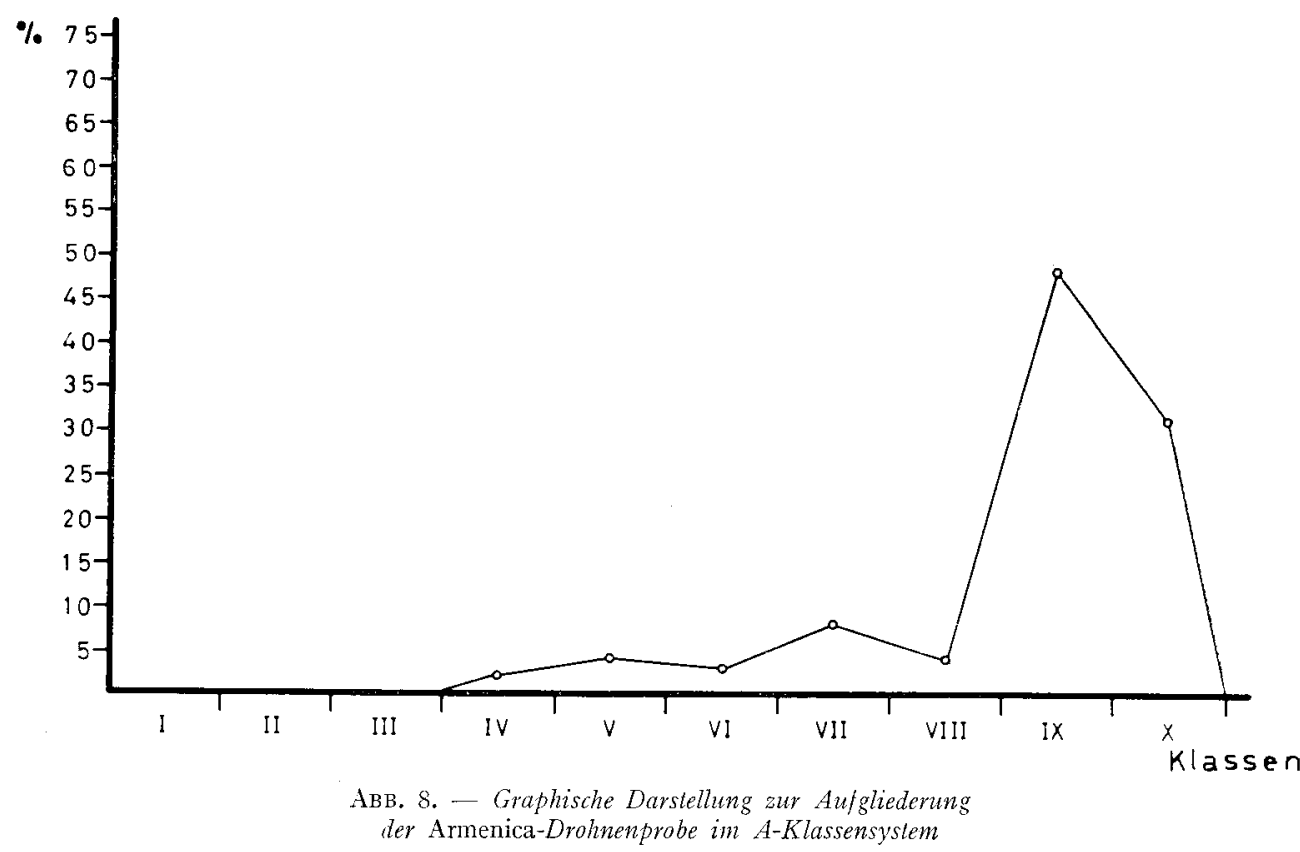

Fis. 8. - Répartition des males de la race Armenica dans le système $A$

Bei der Armenica finden wir keine kleinen Seitenflecken. Die Verdunkelung des Spiegelchens im 5. Tergit erscheint früher als bei anderen geographischen Rassen.

Die Melanisierung des 3. Tergits beginnt gleichzeitig von den Buchten und von der Mitte aus. Am 3, 4. und 5. Tergit beginnt die Melanisierung an den Seitenflecken und verläuft entlang dem Seiten-Sattelstreifen, Bei der A-VII und A-VIII Klasse existieren neben den normalen Inseln noch parallele Inseln in der Seitenflanke. Das ist eine Besonderheit der Armenica. Diese zusätzlichen Inseln treten in der Klasse A-IX sogar am 4. Tergit auf. 
Eine sehr starke Tendenz zu schmalen, aber doch tiefen gelben Seiteneinsprüngen bemerken wir schon in der Klasse A-VII. Auch hier sind die zusätzlichen Inseln ungewöhnlich lang.

\section{f) Geographische Rasse A. m. caucasica GoRbatschew I9Io}

Die Caucasica ist bekannt als graue Gebirgsbiene. Nach der Ansicht von PaLLAS (Ig62) (zit. bei GoETzE, Ig64), der sie als $A$ pis $m$. var. remipes bezeichnete, ist sie vielgestaltig und bunt.

Von BUTTEL-REEPEN (Igo6) bezeichnete die Caucasica als " ein Schmerzenskind der Systematik, da alle Färbungen von gleichmässig-dunkel bis leuchtend-gelb gebändert auftreten. Bei den gelb-gebänderten Formen besteht eine grosse Ähnlichkeit mit der Ligustica $"$.

ZANDER (I923) sagte, dass die Remipes-Drohnen eine grosse Ähnlichkeit mit Carnica-Drohnen haben.

SkoRIkow (I929) behauptet, dass die Caucasica ein Überbleibsel aus der Tertiärzeit sei.

In den vergangenen Jahrzehnten wurden die Bezeichnungen $A$. mell. caucasica und $A$. mell. remipes häufig synonym verwendet. Nach heutiger Auffassung findet sich die dunkle, als Caucasica bezeichnete Form an der nördlichen Flanke des Kaukasus, während die gelbe Form der geographischen Rasse Remipes suidlich des Kaukasus nachweisbar ist.

Meine Probe stammte aus der Sammlung des Bonner Institutes. Sie enthielt nur Tiere der Klasse A-IX mit Inseln und der Klasse A-X, die ganz melanisiert waren. Von dieser Probe gebe ich keine Kurve an, da die Drohnen nur diesen beiden Klassen zugehören. Das Verhältnis der Klassen ist A-IX $=45 \%$ und A-X $=55 \%$ Auch ZANDER (I923) fand in seinem Material $44 \%$ der Drohnen mit Inseln. Das entspricht meinen Befunden. Die nachträgliche Analyse der Zeichnungsmuster von Caucasica-Drohnen (Königin von Glushkow, durch Prof. RutTrer zur Verfügung gestellt) erbrachte ebenfalls nur Exemplare von Klasse A-IX und A-X.

\section{g) Geographische Rasse A. m. carnica POLLM. I879}

Die Camica bildet eine der grössten geographischen Rassen Europas. Sie besiedelt ganz Süd-Ost-Europa bis zur Ukraine und ist durch intensiven Export in der ganzen übrigen Welt verbreitet worden.

Das Aussehen und das Färbungsmuster dieser Biene variiert in verschiedenen geographischen Bereichen. In den Gebirgen finden sich vorwiegend dunkle Typen, während in Niederungsgebieten und Ebenen mehr oder weniger gelb gezeichnete Formen verbreitet sind. Der dunklen Form gehören die Drohnen von Probe $C a_{1}$ und $C a_{2}$ an. Ausser einigen wenigen Drohnen von $C a_{2}$, die ich in Klasse A-VIII einordnete, konnte ich nur Exemplare der Klassen A-IX und A-X finden. Neben der dunklen Gebirgsform wurde die durch gelbe Zeichnungsmuster geprägte Carnica Biene häufig in der Literatur erwähnt, z.B. hat BU'TTEL-REEPEN schon I9I5 auf sie hingewiesen, aber er war der Ansicht, dass solche Bienen (Banater, Herzegowiner usw.) Ergebnisse von Kreuzungen zwischen gelben und dunklen Rassen seien (z. B. Ligustica $\times$ Carnica). 
FIs'TEAG (I937) beschreibt die Bienen Rumäniens und nimmt an, dass es sich hier um Carnica-Bienen handelt, obwohl sie gelb gezeichnet sind. FARCAS (r938) stellte ebenfalls diese gelbe Carnica in Rumänien fest und nahm Kreuzungen mit der Ligustica vor. GoE'TzE (I950) schreibt in seiner Camica-Monographie, dass die gelbe Farbe " als altes eigenes Erbgut " der Carnica zu gelten hätte. RuTTwER (I95I) sieht in dieser gelben Zeichnung keinen Hinweis für eine Bastardierung mit Ligustica-Bienen.

Die eingehendste Untersuchung stammt von BAKK (I955). Er analysierte ein umfassendes Bienenmaterial aus ganz Ungarn und fand $46 \%$ ohne gelbe Zeichnung, $35 \%$ mit geringer, I $\%$ mit deutlichen gelben Flanken und $7 \%$ mit einem gelben Ring, I \% hatte 2 gelbe Ringe. Fir ist der Ansicht, dass es sich bei diesen Bienen um Carnica handelt. Richar (I96I) befasst sich mit der gelben Zeichnung der Carnica Jugoslawiens. Auch er findet dunkle Formen im Gebirge und mit gelben Zeichen versehene Bienen in den Ebenen, sowie an den Küsten der Adria.

RUTTNER (I962, I963) analysierte Tergite von Carnica-Arbeitsbienen und sagte : " Anders als bei der Ligustica werden bei der Carnica so gut wie nie Drohnen mit gelben Ringen gefunden ".

Für meine Analyse der Zeichnungsmuster hatte ich eine Drohnenprobe $\left(\mathrm{Ca}_{3}\right)$ aus dem Banat zur Verfugung. In ihr fand ich Exemplare der Klassen A-II bis A-VII, A-VI fehlte (Abb. 9). Das Maximum lag in der Klasse A-V. Im vorliegenden Fall haben wir es mit einer extrem gelben Carnica zu tun, die durch ihre Farbzeichnung der Ligustica ähnelt. Finige Autoren, unter anderen BELDAME (I95I) wollen diese Biene als selbständige Rasse einstufen. Dennoch bestehen kleine Unterschiede, die detailliert aufzuzeigen mir wegen der geringen Drohnenprobe unmöglich war. Ich habe sie in mein allgemeines A-System eingeordnet.

\section{h) Geographische Rasse A. mellifica (Nigra) I898}

Mellifica war ursprünglich in ganz Nordwest Europa verbreitet. Sie dringt auch in Russland weit nach Osten vor. Obwohl sie die am weitesten verbreitete Rasse darstellt, hat sie doch heute geringere Bedeutung für die Bienenzucht als $\mathrm{z}$. $\mathrm{B}$. die Carnica oder Ligustica. Heute fällt es schwer, reine Mellifica zu finden, da die Carnica und Ligustica überallhin importiert wurden.

Die in Norddeutschland frïher vorherrschende Heidebiene soll sehr einheitlich gewesen sein, das heisst, frei von gelben Zeichen. Heute allerdings findet man diese Mellifica-Biene nicht mehr in reiner Form.

Eine Drohnen-Probe von Mellifica aus dem Institut in Bonn $\left(N_{1}\right)$ soll von Heidebienen stammen. Sattelfiguren konnte ich bei dieser Probe nur in den Klassen A-IX und A-X feststellen.

Eine 2. Probe $\left(N_{2}\right)$ zeigte ähnliche Sattelfiguren und wurde in die Klasse A-IX und A-X eingeordnet (Tab. 3).

\section{i) Geographische Rasse A. m. ligustica SPIN. I808}

Die Bienen dieser geographischen Rasse sind bei den Praktikern als Italiener bekannt. Ihr Ursprungsgebiet ist die Apenninen-Halbinsel. Der Name der Rasse stammt von Spinola (I808), er wendet die Benennung auf die gelben Bienen Ligu- 


\begin{tabular}{l|l}
\hline $\begin{array}{l}\text { Anz. } \\
(\%)\end{array}$ \\
\hline
\end{tabular}

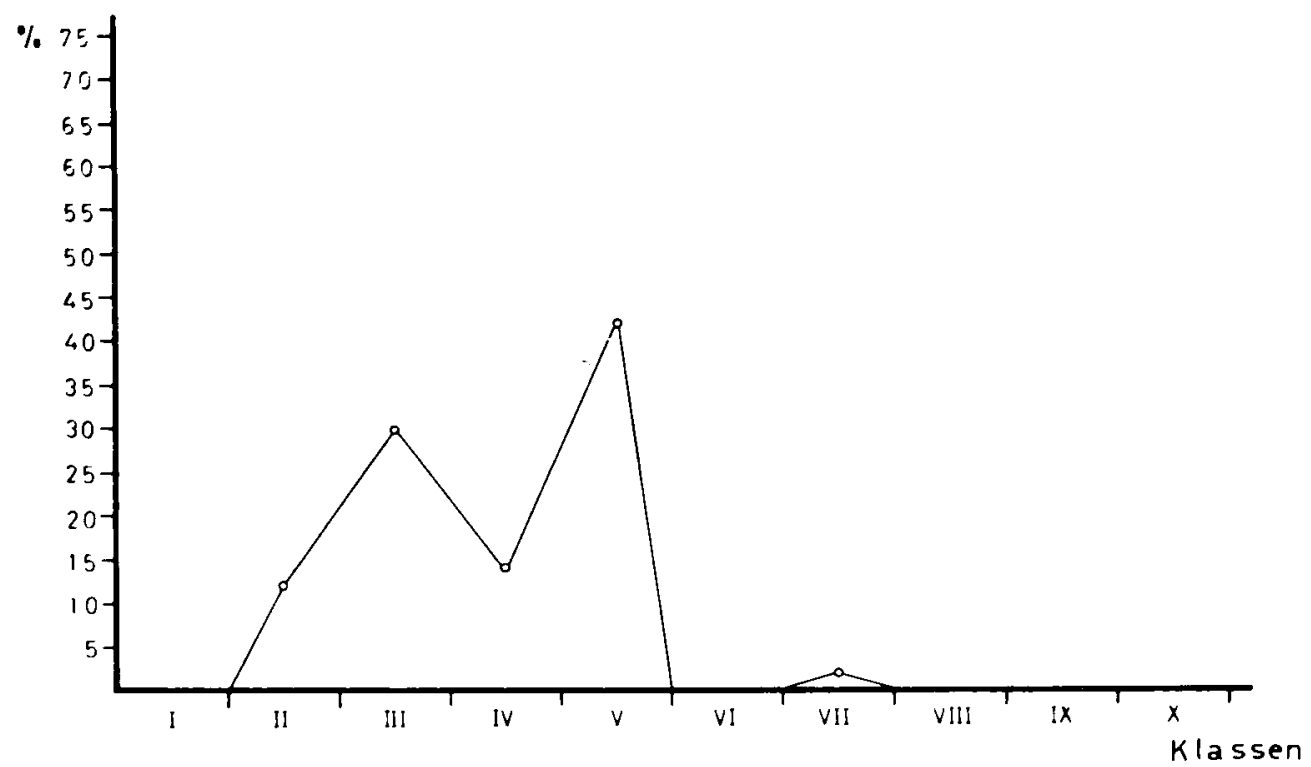

AвB. 9 -Tabelle mit zahlenmässiger und prosentualer Augliederung der 3 Carnica-Drohnenproben in A-Klassensusten

Die Finordnung der dritten, aussergewöhnlich hellen Carnica probe in das Klassensystem wird in der Kurve dargestellt. Diese Probe stammte aus dem Banat

FIG. 9. - Représentation numérique el en pourcentages de 3 séries de mâles de la race Carnica dans le système $A$

Dans la courbe est représentée la série, anormalement claire, de race Carnica Cette série provient de la région de Banat 
riens an. Aber nicht nur hier, sondern auch in anderen Teilen Italiens findet man gelbe sowie dunkle Bienen. Die Pigmentierung zeigt starke Schwankungen zwischen hell und dunkel.

\section{TABLEAU 3}

Répartition numérique et en pourcentages des 2 séries de mâles de race Mellifica (Nigra) dans le système $A$

TABELLE 3

Zahlenmässige und prozentuale Verteilung der 2 Mellifica (Nigra) Drohnenproben im A-Klassensystem

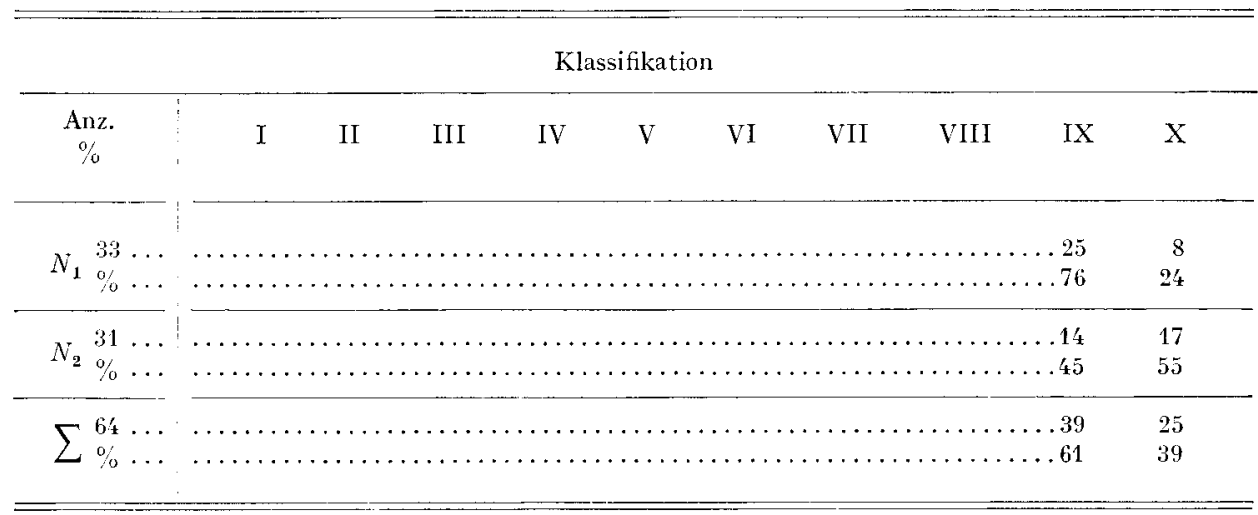

Beschreibungen dieser Rasse finden wir bei von BuTTEL-REEPEN (I9I5), BOveri (I9I5), Zander (I923), Armbruster (I923), Goetze (I95I), Giavarini (I953) und anderen.

Über die Entstehung der geographischen Rasse herrschen Meinungsverschiedenheiten. Von ButTel-REEPEN (Igo6) meint, dass die Ligustica durch Kreuzung zwischen Mellifica und Fasciata entstanden sei. Er gliedert diese Rasse in drei Formen auf.

GoETZE fand bei Ligustica-Drohnen die Abstufung von Drohnen mit drei gelben Tergiten bis zu fast vollkommen dunklen Exemplaren und konstatierte in biometrischer Hinsicht eine grosse Ähnlichkeit mit Carnica, ein Unterschied besteht nur in der Färbung.

GIAVARINI schildert, dass die Ligustica-Drohnen alle Farbstufen von gelb bis schwarz enthalten.

Neben dieser variablen Ligustica der natürlichen geographischen Rasse spielt in den letzten hundert Jahren eine durch kommerzielle $Z$ üchtungsbetriebe vermehrte und in aller Welt stark verbreitete Form der Ligustica eine grosse Rolle, die sogenannte " goldene " oder " Aurea-Biene " (ROTTER, I9I9). ZANDER (I923) vertritt dieselbe Meinung wie RotTER und betrachtet diese Bienen als eine Spielart der Ligustica. Bruder ADAM (I95I) äussert, dass die "goldene "Italiener keineswegs eine Italiener Biene sei, sondern durch Kreuzung zwischen der italienischen und anderen dunklen Rassen entstanden sei. Durch intensive Selektion und kontrollierte Paarung erhielt man in den USA noch hellere Formen, deren Hinterleiber fast ganz melaninfrei sind. Natürlich bleibt die Grundzeichnung der Melanisierung erhalten. 
Diese Einführung war notwendig, da meine Ligustica-Drohnenproben alle von diesen Zuchtstämmen abstammen. Wie man aus Tabelle I ersehen kann, erhielt ich zwei meiner Proben aus Italien von bekannten Königinnenzüichtern, die anderen Proben aus Deutschland. In der Vorklassifizierung wurde offenkundig, dass diese Form der Ligustica in ein einheitliches System mit den anderen geographischen Rassen nicht einzuordnen ist. Aus diesem Grunde stellte ich für die Ligustica ein eigenes 9 bzw. Io-klassiges System auf.

Die Sattelfiguren der Ligustica-Form ersehen wir aus der Abb. 3, die analytische Darstellung der 5 Proben aus $\mathrm{Abb}$. Io. Die $L_{\mathrm{L}}$-Probe schwankt von $\mathrm{B}-\mathrm{I}$ bis B-VI. Wir erhalten 2 Maxima. Das Hauptmaximum befindet sich in der Klasse B-I, zwischen den Klassen B-I und B-V liegt ein breites Minimum. Vermutlich stammten die Eltern dieser Königin aus zwei sehr heterogenen Farbmuster-Klassen. Aus diesem Grunde haben wir hier eine Erscheinung von der Art, wie sie bei einer Kreuzung zwischen zwei Rassen häufiger auftritt.

Bei der Probe $L_{2}$ liegt das Maximum in der Klasse B-III. Die Probe erstreckt sich über die Klassen B-II bis B-V. In die Klassen B-IV und B-V sind nur einzelne Exemplare eingestuft. Die Drohnen der Probe $L_{3}$ sind zwischen B-I und B-III einzuordnen. Die Kurve der Probe $L_{4}$ verläuft zwischen B-I und B-IV und hat ihr Maximum in B-II, ihr Minimum bei B-III. Dann steigt die Kurve zu einem Nebenmaximum in B-IV an.

Die Sattelfiguren der Probe $L_{5}$ umfassen die Klassen von B-II bis B-V und haben ihr Maximum in B-III.

Besonders charakteristische Kennzeichen der Ligustica-Drohnen : Der Spiege1 des 2. Tergites ist bei der Klasse B-III schon geschlossen, obwohl der Iittelstreifen des 3. Tergites noch melaninfrei ist.

Die Melanisierung geht fast immer von der Mitte des Mittelstreifens aus und setzt sich fort in Richtung der Buchten und des Sattelstreifens.

Ein unabhängiger Ausgangspunkt der Melanisierung befindet sich zwischen dem Seiten-Sattelstreifen und dem Seitenflecken neben dem Stigma. Dies gilt besonders für die Proben aus Italien. Bei den Proben aus Deutschland ist diese Eigenart weniger stark ausgebildet, aber dennoch vorhanden.

\section{III. - DISKUSSION}

Die Einzelbefunde der vorhergehenden Abschnitte ergeben, dass die Musterbildung der Drohnentergite, isoliert genommen, kein ausreichendes Merkmal für die taxonomische Trennung der Mehrzahl der hier untersuchten geographischen Rassen darstellt. Nur die Farbzeichnung der Ligustica-Drohnen bietet so viel charakteristische Eigenart, um für diese Rasse mustermässig eine Sonderstellung zu rechtfertigen.

Diese Eigenart der Ligustica spricht gegen die Annahme AlBERS (I952) von dem Ursprung von Sahariensis als Nachkommen von Ligustica-Importen nach Nordafrika. Weiterhin kann auf Grund der Sonderstellung der Ligustica ihre enge Zugehörigkeit zur Cypria- und Fasciata-Rasse, wie sie von ZANDER (I923) und MACKensen (I943) vermutet wurde, nicht bestätigt werden. Die Schwierigkeit für eine umfassendere Beurteilung von Ligustica liegt in der bereits stark fortgeschritte- 

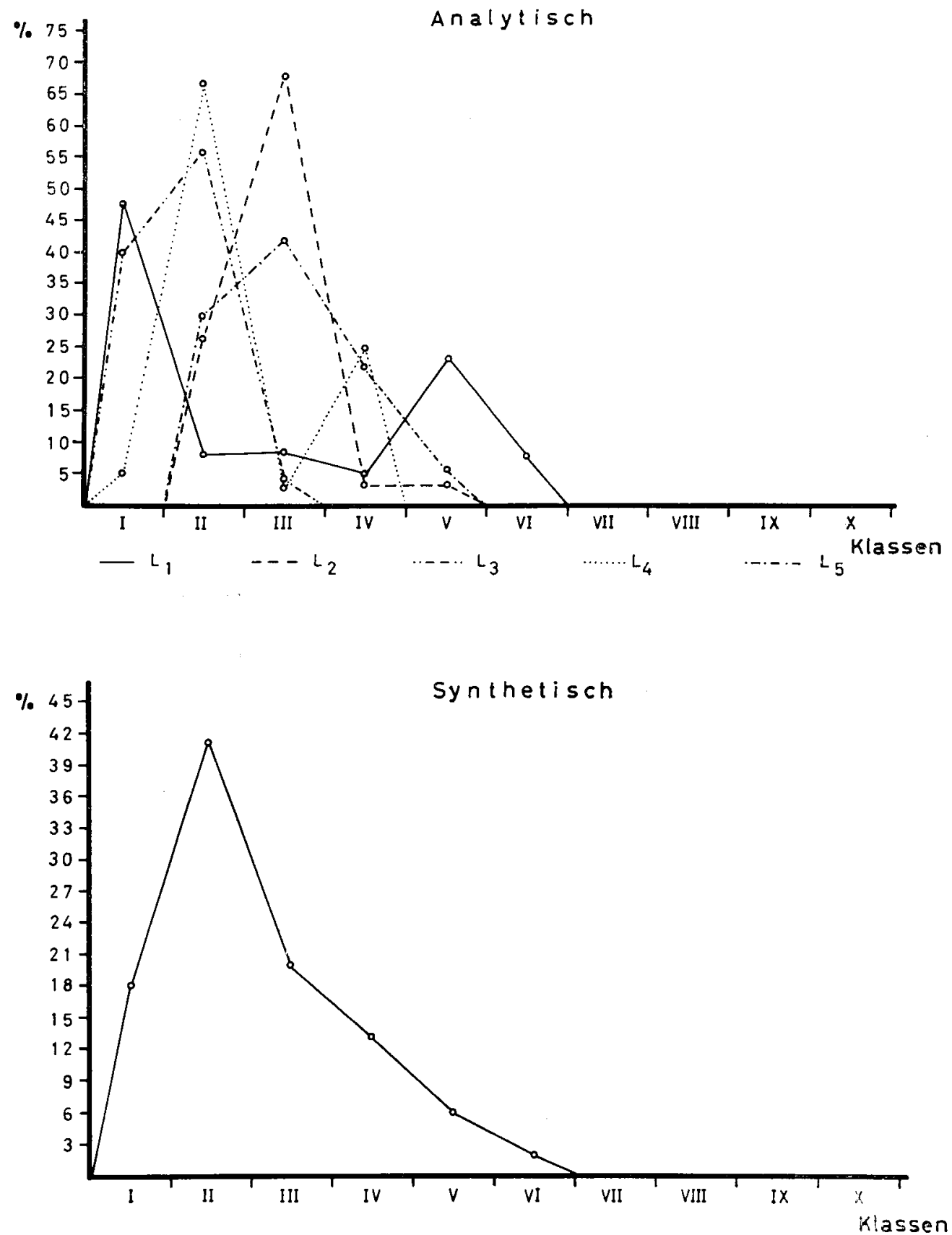

Aвв. го. -- Graphische Darstellung (analytisch und synthetisch) der Verteilung der 5 Ligustica-Drohnenproben im B-Klassensystem der Tergit-Zcichnungsmuster

FIG. Iо. - Répartition graphique de 5 séries de mâles de la race Ligustica dans le système $B$ 
nen ziichterischen Beeinflussung dieser Rasse, die sich stark nach der Vorstellung der Käufer orientierte. Es ist daher durchaus denkbar, dass ich bei meinem Ligustica Material nur einen Ausschnitt der Gesamtbreite des Zeichnungsmusters erfassen konnte. Während bei Ligustica-Material italienischer Herkunft drei gelbe abdominale Ringe das Maximum darstellen, sollen sich bei amerikanischen Ligustica-Nachzuchten sogar Formen mit 5-6 gelben Ringen finden. Doch weiss man bei diesem Material nicht sicher, wieweit andere helle, mediterrane Bienenrassen (Cypria, Syriaca) aus anderen Importen eingekreuzt worden sind.

Ein erheblicher Nachteil für die Beurteilung der Musterbreite der persischen Drohnen ist die Kleinheit meiner Proben. Dennoch ist es eigenartig, dass von den wenigen Tieren ( $n=2 \mathrm{I}$ ) das gesamte Klassensystem beansprucht wird. Ob fïr die Bienen des persischen Raumes eine Abtrennung als eigenständige Rasse berechtigt ist, lässt sich heute wegen der fehlenden biometrischen Untersuchungen noch nicht sagen. Das Vorkommen der 3 übrigen Apis-Arten im südost-asiatischen Raum könnte zu der Vermutung führen, dass der Bereich von Afghanistan und Persien das Entstehungszentrum der Art Apis mellifica darstellt. Aus diesem Kern wäre dann die Ausbreitung der Honigbiene unter Ausprägung geographischer Rassen in nördliche und westliche Richtung erfolgt.

Inwieweit die Orient-Rasse Apis mellifica remipes den persischen Raum mit um-

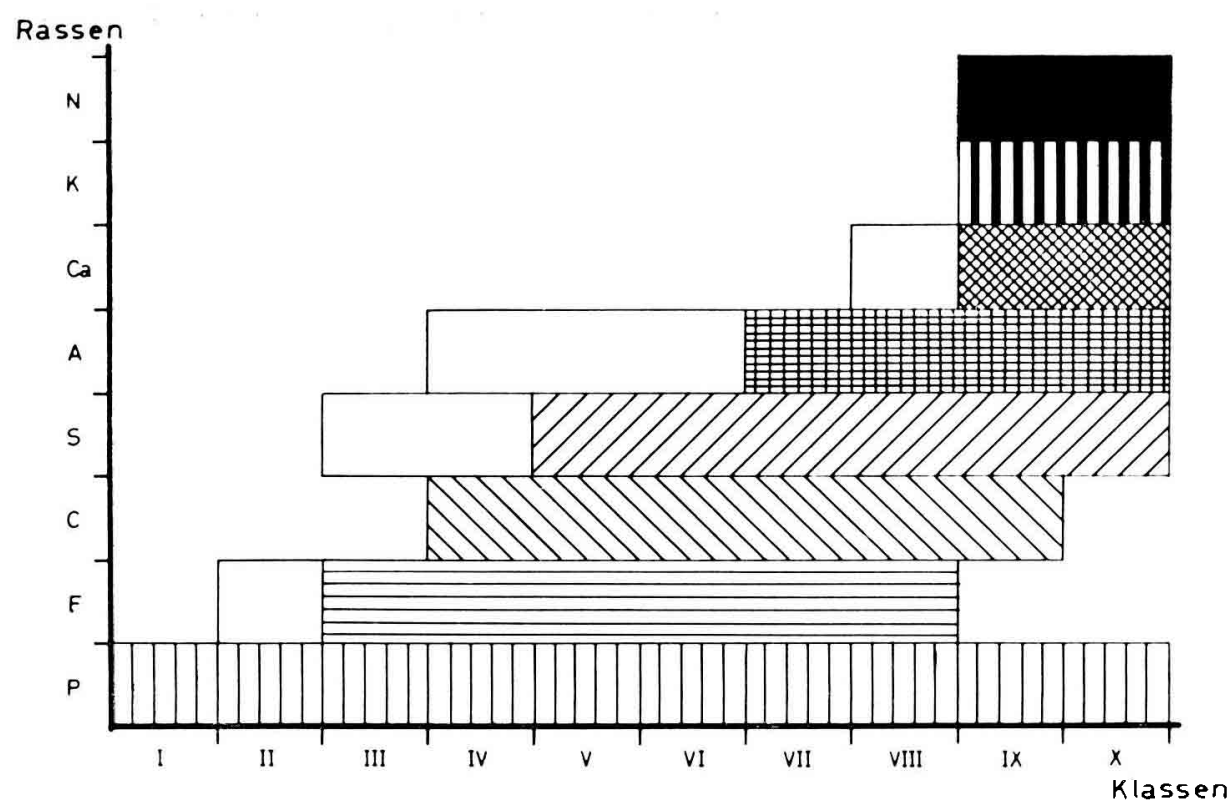

ABB. I1. - Zusammenstellung der Klassenbreiten für die untersuchten geographischen Rassen

Weisse Rechtecke umfassen weniger als $5 \%$ der Gesamtproben.

$$
\begin{aligned}
& P=\text { Persica } \\
& F=\text { Fasiata } \\
& C=\text { Cypria } \\
& S=\text { Sahariensis }
\end{aligned}
$$

$$
\begin{aligned}
& A=\text { Arnenica } \\
& \text { Ca }=\text { Carnica } \\
& K=\text { Cancasica } \\
& N=\text { Nigra }
\end{aligned}
$$

FIG. II. - Vue d'ensemble des groupes correspondant aux races géographiques étudiées

Les rectangles blancs indiquent un pourcentage d'individus inférieur à $5 \mathrm{p}$. roo. 
fasst, lässt sich noch nicht sagen, da bisher noch zu wenige rassendiagnostische Arbeiten über das Bienenmaterial jenes Bereiches vorliegen. Auch die früheren Beschreibungen des äusseren Habitus der dort heimischen Bienen sind so vage, und z. T. widersprüchlich, dass sie nicht zur Abgrenzung des Rassenbereiches der Apis mellifica remipes herangezogen werden können.

$\mathrm{Abb}$. II gibt die stufenweise Verdunkelung bzw. Melanisierung der Drohnen verschiedener geographischer Rassen von der Fasciata bis Mellifica (Nigra) wieder. Bemerkenswert ist das Vorherrschen der helleren Formen im subtropischen Bereich. Alle nördlichen Formen - Mellifica, Caucasica, Carnica - sind dunkel gezeichnet. Die hellere Spielart der Carnica, die sgn. Banater Biene, stammt aus dem Bereich der panonischen Ebene des Balkan, die für ihr sommerlich heisses Kontinentalklima bekannt ist.

Eine Abweichung von diesem Sachverhalt bietet die geographische Rasse Apis mellifica intermissa im nordafrikanischen Küstengebiet. Von dieser Rasse habe ich zwar keine Probe untersuchen können, doch wird die dort heimische Biene von zahlreichen Autoren (von BUTTEL-REEPEN, Igo6; BALDENSPERGER, I933; AlBER, I952; Bruder ADAM, I96r, I964) als recht dunkel beschrieben. Ob die von mir untersuchte Sahariensis nur eine in den Oasen vorkommende helle L,okalform der dunklen Intermissa darstellt kann hier nicht bestimmt werden.

Somit kann festgestellt werden, dass jede geographische Rasse in Hinsicht auf das Zeichnungsmuster des Drohnen-Abdomens wohl einen bestimmten Bereich des gesamten vorkommenden Musterspektrums einnimmt. Diese rassetypischen Bereiche überschneiden sich aber erheblich und lassen dadurch eine Trennung der geographischen Rassen allein mit Hilfe von diesem Merkmal nicht zu. Nur die spezifische Zeichnung der züchterisch beeinflussten Ligustica-Drohnen erlaubt ihre Identifizierung neben den Drohnen der anderen hellen, gelbringigen Bienenrassen. Möglicherweise würde eine Auswertung von züchterisch unbeeinflussten Ligustica-Drohnenproben aus anderen Bereichen Italiens, in denen sich mehr Exemplare der Klassen nahe B-X befänden, zu einer Angleichung des Ligustica-Systems an das allgemeinere A-System der anderen Rassen fiihren.

\section{C. - DIE PHÄNOANALYSE DER ABDOMINAL-TERGITE VON DROHNEN}

\section{AUS REZIPROKEN KREUZUNGEN VERSCHIEDENER GEOGRAPHISCHER}

\section{RASSEN DER HONIGBIENE, (APIS MELLIFICA I..)}

I)ie Ergebnisse von Teil I weisen darauf hin, dass das Melanisierungsmuster eine artspezifische Eigenschaft ist, während die Ausfüllung des Musters mit Melanin, also der Melanisierungsgrad, eine rassische Eigenart darstellt. Die obengenannten Frgebnisse sprechen für eine polygene Basis der Musterausbildung durch Melanineinlagerung. Diese Annahme stützt sich auf Befunde von der Verteilung eines zahlenmässig umfangreichen Drohnenmaterials von einer Königin in einer Zufallskurve, wenn man die Anordnung der Tiere nach zunehmender Melanisierung der AbdominalTergite in dem Klassensystem vornimmt. Weiterhin muss berïcksichtigt werden, dass bie Festlegung der Klassen willkürlich erfolgen muss, da zwischen den herausgegriffenen Melanisierungsstufen gleitende Übergänge nachweisbar sind. 
Nun ist es von Interesse, die Nachkommenschaft von zwei in ihrer Ausfärbung bekannten Isltern in Hinblick auf die Häıfigkeit der auftretenden unterschiedlichen Melanisierungsstufen innerhalb dieser Nachkommen zu prüfen. Es ethebt sich diese Frage speziell bei der Bastardierung von Tieren, die zwei Rassen angehören, die jedoch in ein Klassensystem einzuordnen sind. I)as ist z.B. bei Tieren der Carnicaund der Sahariensis-Rasse der Fall.

Ebenso kann eine Prüfung der Nachkommenschaft von zwei Elterntieren aus zwei verschiedenen Rassen, die zugleich noch zwei verschiedenen Klassensystemen in Hinblick auf das Abdominalzeichnungsmuster angehören, Aufschluss geben, ob sich eines der Pigmentierungssysteme in der $\mathrm{F}_{1}$-Generation durchsetzt, oder ob noch ein drittes, eventuell intermediäres, Melanisierungssystem möglich ist.

Auf die Mehrzahl der frïheren Arbeiten und Berichte mit Angaben iiber die Iirgebnisse von Rassenkreuzungen der Honigbiene kann aus zwei Gründen nicht zurückgegriffen werden. Iis standen den Untersuchern dieses Sachverhalts nur Belegstellen mit einem mehr oder minder grossen, in jedem Fall aber unkontrollierbaren Grad an Zuflugsicherheit zur Verfügung. Weiterhin war vor ca. Io Jahren bis zu den Untersuchungen von Taber (I954), Alber, Jordan, RUTrsier F.u.H. (I955), PEER (I956) u.a. noch unbekannt, dass die Bienenköniginnen sich mit zahlreichen I)rohnen auf dem Hochzeitsflug paaren. Ihre Nachkommenschaften stellen somit ein Konglomerat von Halbgeschwistergruppen mit jeweils verschiedenen Vätern clar.

Nur in der Arbeit von ROBERTS (I950) wurden schon systematische Kreuzungen mit Hilfe der instrumentellen Sameniibertragung bei der Bienenkönigin nach entsprechend intensiver vorangegangener Inzucht vorgenommen. Da für meine Untersuchungen diese Methode ebenfalls zur Verfügung stand, konnten systematische reziproke Kreuzungen zwischen Tieren verschiedener geographischer Rassen durchgeführt werden. (I)ie instrumentellen Besamungen für die im nachfolgenden Abschnitt beschriebenen Untersuchungen wurden entgegenkommenderweise von Herrn Dr. I)RESCHER durchgeführt).

\section{I. - Arbeitsmethoden}

\section{a) Material und Methode}

Verwendung fand in Bonner Institut gehaltenes Bienenmaterial der Rassen Ligustica, Sahariensis und Carnica. Während die für die Kreuzungen verwendeten Drohnen einwandfrei vor dem Besamungsvorgang klassifiziert waren und einer Klasse im Zeichnungsmustersystem zugeordnet werden konnten, war für die Festlegung des Melanisierungsgrades der Königin das Drohnensystem nur indirekt verwendbar, da die Königinnen nicht dieses typische, gut ausgeprägte Zeichnungsmuster wie die Drohnen zeigen. Deshalb wurde für den Melanisierungsgrad der Königinnen folgender Masstab gewählt : Von jeder Königin wurde eine Drohnenprobe im Hinblick auf ihre Pigmentierung ausgewertet. Man erhielt so einen Überblick von den Erbanlagen dieser Königin für die Melanisierung des Abdomens ihrer Sohn-Drohnen. Als Finstufung aller ihrer Tochterköniginnen wurde die Klasse gewählt, die bei der Verteilungskurve der Bruder-Drohnen den extremsten Wert erfasste. So gehörten z.B. die Bruder-Drohnen der Königin Nr.5, d.h. die Söhne von Königin B 1 I 5 $(S \times C a$ ) siehe Tabelle 6, den Klassen A-V bis A-VIII an. Die Königin wurde besant mit einem Carnica-Drohn aus Klasse A-IX. Die Stellung der Königin wurde im Klassensystem mit dem Wert $\mathrm{A}-\mathrm{V}$ eingestuft.

Die bereits vor Beginn der Versuche stark ingezüchteten Königinnen der drei vorgenannten Rassen wurden vor ihrer Bastardierung während zwei Generationen durch Paarung der Königinnen mit nur einem Drohn weitergeführt (z.T. Bruder-Drohn) siehe Tabelle 4. Alle zur Besamung verwen- 
TABLEAU 4

Tableau des unions consanguines réalisées par insémination artificielle chez les lignées de Carnica, Ligustica et Sahariensis

TABELLE 4

$\ddot{U}$ bersicht der durch instrumentelle Besamung durchgeführten

Inzucht der Versuchslinien der Carnica-, Ligustica-und Sahariensis-Rasse

\begin{tabular}{|c|c|c|c|c|c|c|c|}
\hline & $\begin{array}{c}\text { Besam. } \\
\text { Nr. }\end{array}$ & $\begin{array}{c}\text { Geograph. } \\
\text { Rasse }\end{array}$ & $\begin{array}{l}\text { Herkunft } \\
\text { d. } q\end{array}$ & $\begin{array}{l}\text { Herkunft } \\
\text { d. } \delta^{2} \sigma^{*}\end{array}$ & $\begin{array}{l}\text { Anz. } \\
\text { d. } \hat{\partial} \sigma^{*}\end{array}$ & $\begin{array}{l}\text { Besam. } \\
\text { Datum }\end{array}$ & $\begin{array}{l}\text { Eiablg. } \\
\text { Datum }\end{array}$ \\
\hline Inzucht I & $\begin{array}{l}\text { B-69 } \\
\text { B-68 } \\
\text { B-77 }\end{array}$ & $\begin{array}{l}\text { Ligustica } \\
\text { Sahariensis } \\
\text { Carnica }\end{array}$ & $\begin{array}{c}\text { AH-10 } \\
\text { B-45 } \\
Z N-139\end{array}$ & $\begin{array}{c}\mathrm{AH}-10 \\
\mathrm{~B}-5 \mathrm{t} \\
\mathrm{B}-50\end{array}$ & $\begin{array}{l}1 \\
2 \\
1\end{array}$ & $\begin{array}{r}12-6-64 \\
9-6-64 \\
17-6-64\end{array}$ & $\begin{array}{l}19-6-64 \\
16-6-64 \\
25-6-64\end{array}$ \\
\hline Inzucht II & $\begin{array}{c}\text { B-116 } \\
\text { B-95 } \\
\text { B-120 }\end{array}$ & $\begin{array}{l}\text { Ligustica } \\
\text { Sahariensis } \\
\text { Carnica }\end{array}$ & $\begin{array}{l}\text { B-69 } \\
\text { B-68 } \\
\text { B-77 }\end{array}$ & $\begin{array}{l}\mathrm{AH}-10 \\
\mathrm{~B}-13 \\
\mathrm{ZN}-71\end{array}$ & $\begin{array}{l}1 \\
1 \\
1\end{array}$ & $\begin{array}{l}15-7-64 \\
14-7-64 \\
21-7-64\end{array}$ & $\begin{array}{l}23-7-64 \\
25-7-64 \\
31-7-64\end{array}$ \\
\hline
\end{tabular}

TABLEAU 5

Origine de la génération hybride

TABELLE 5

Das Ausgangsmaterial für die Hybrid-Generation

\begin{tabular}{|c|c|c|c|c|c|c|}
\hline $\begin{array}{c}\text { Besam. } \\
\text { Nr. }\end{array}$ & Kreuzung & $\begin{array}{c}\text { Herkunft } \\
\text { d. }+\end{array}$ & $\begin{array}{c}\text { Herkunft } \\
\text { d. } \delta \widehat{\delta}\end{array}$ & $\begin{array}{c}\text { Anz. } \\
\text { d. } \delta \delta\end{array}$ & $\begin{array}{l}\text { Besam. } \\
\text { Datum }\end{array}$ & $\begin{array}{l}\text { Eiablg. } \\
\text { Datum }\end{array}$ \\
\hline B-139 & $L \times S$ & B-116 & B-13 & 1 & $18-8-64$ & $31-8-64$ \\
\hline B-114 & $S \times L$ & B -68 & $\mathrm{AH}-10$ & 1 & $15-7-64$ & $23-7-64$ \\
\hline B-109 & $L \times C a$ & B-69 & $\mathrm{ZN}-71$ & 1 & $15-7-64$ & $23-7-64$ \\
\hline B-102 & $C a \times L$ & B-77 & $\mathrm{AH}-10$ & 1 & $20-7-64$ & $30-7-64$ \\
\hline B-115 & $S \times C a$ & B- 68 & $Z N-71$ & 1 & $15-7-6 / t$ & $23-7-6^{\prime}+$ \\
\hline B-119 & $\mathrm{Ca} \times S$ & B-77 & B-13 & 1 & $21-7-64$ & $3-8-6^{\prime} t$ \\
\hline
\end{tabular}

TABIEAU 6

Tableau des reines ayant produit les mâles hybrides utilisés pour la classification

TABELLE 6

$\ddot{U}$ bersicht der Königinnen, die die zur Klassifzierung herangezogenen Hybrid-Drohnen erzeugten

\begin{tabular}{|c|c|c|c|c|c|}
\hline Nr. d. 9 & Kreuzung & $\begin{array}{l}\text { Herkunft } \\
\text { d. } 9\end{array}$ & $\begin{array}{l}\text { Eiablage } \\
\text { Beginn }\end{array}$ & $\begin{array}{c}\text { Schlüpfdatum } \\
\hat{\partial \hat{\sigma}}\end{array}$ & $\begin{array}{c}\text { Anzahl } \\
\hat{\delta} \delta\end{array}$ \\
\hline 1 & $L \times S$ & B-139 & $20-10-64$ & $26-11-6 t$ & 25 \\
\hline 2 & $S \times I$ & B-114 & $2-9-6^{\prime}$ & $26-9-64$ & 80 \\
\hline 3 & $L \times C a$ & B-1.09 & $5-9-6^{\prime} t$ & $28-9-64$ & 41 \\
\hline 4 & $C a \times L$ & B-102 & $3-9-6^{\prime} t$ & $26 \cdot 9 \cdot 64$ & 59 \\
\hline 5 & $S \times C a$ & B-115 & $31-8-6^{\prime}$ & $26-9-6^{\prime} 4$ & 48 \\
\hline 6 & $\mathrm{Ca} \times S$ & B-119 & $18-9-6^{\prime}$ & $6-10-6 / 4$ & 48 \\
\hline
\end{tabular}


deten Drohnen gelangten in Wabentaschen zum Schlupf ; so war ihre Herkunft sicher. Nur Drohnen mit reichlich Spermienvorrat kamen zur Verwendung. Die Besamung mit dem Sperma eines Drohns ist technisch wohl möglich, doch veranlasst der geringe Füllungszustand der Spermatheka der Königinnen das Volk während der Sommermonate leicht zur stillen Umweiselung. Intensive $\mathrm{CO}_{2}$-Behandlung, 2-3 Tage nach der Besamung, brachte auch diese mengenmässig unzulänglich besamten Königinnen bald in Eiablage.

Die Haltung der Ableger erfolgte in 3 -Waben-Ablegerkästen. Von den besamten Königinnen gelangten $89 \%$ zur Eiablage. Der Beginn der Eiablage lag zwischen dem I 3.- I9. Tag nach dem Schlüpfen. Nach den zwei Inzucht-Generationen führte ich die reziproken Kreuzungen (siehe Tab. 5) durch Besamung mit je einem Drohn der anderen gewünschten Rasse durch. Hier war der Besamungserfolg $83 \%$. Von jeder Kreuzung wurden zur Sicherheit zwei Königinnen angesetzt, da diese leicht drohnenbrütig werden konnten und so unbrauchbar wurden. Die interessierende Generation der Bastardköniginnen erhielt ich erst Ende August 1964. Um von ihnen die notwendigen Drohnen zu erlangen, blieb nur der Weg über eine vorzeitige Drohnenbrütigkeit der Königinnen offen. Technisch war das möglich durch mehrfache intensive $\mathrm{CO}_{2}$-Behandlung der jungen unbegatteten Königinnen (MACKENSEN und RoBERTS I948). Nach I7-25 Tagen begannen alle so behandelten Königinnen mit der Ablage unbefruchteter Eier, die mir die erforderlichen Drohnen lieferten. Eine nicht mit $\mathrm{CO}_{2}$ behandelte Königin wird zumeist nach mehr als 30 Tagen nach dem Schlüpfen drohnenbrütig, wenn man sie am Ausflug hindert. Häufig wird sie aber vorher schon von den Bienen getötet. Die verdeckelten Drohnenwaben entnahm ich einige Tage vor dem Schlüpfen den Ablegern und brachte sie in Brutschränke mit einwandfrei kontrollierter Temperatur $\left(35^{\circ} \mathrm{C}\right)$ und Luftfeuchtigkeit $\left(55^{-60} \%\right.$ zum Schlupf. Die Einhaltung konstanter Temperatur und Luftfeuchtigkeit während der letzten Entwicklungsphase ist erforderlich, da nach den Untersuchungen von Soose (I954) erhöhte und erniedrigte Temperatur zu einer Veränderung der Melanisierung der Tiere führt.

Die Behandlung, Präparation und zeichnerische Auswertung der Drohnenproben erfolgte nach derselben Methode wie im r. Abschnitt angegeben.

\section{b) Klassensystem für die Beurteilung der Bastard-Drohnen}

Die von den Bastard-Königinnen erzeugten Drohnen liessen sich nicht völlig in die in Teil I angegebenen A- und B-Klassensysteme für die abdominale Melanisierung einordnen. Bei den Drohnen war ein anderer Melanisierungsablauf feststellbar, als bei den rassereinen Tieren. Das erforderte die Einführung neuer Klassen, die in einem eigenen System (C-System, siehe Abb. 3) angeordnet sind. In diesem System stimmen einige der Klassen mit denen im System A und B überein, wie aus der Beschreibung der einzelnen Klassen hervorgeht. Das C-System umfasst auch Io Klassen. Hier ist wieder anzufügen, dass dic Festlegung der Klassen rein subjektiv erfolgen musste. Ebenso kommen kleine Abweichungen bei den verschiedenen Rassenkreuzungen von den im System durch Beschreibung und Zeichnung festgelegten Klassen vor, die bei der anschliessenden Beschreibung der Kreuzungen erwähnt werden.

Klasse C-I : Die Sattelfiguren dieser Klasse sind vergleichbar denjenigen der Klasse B-II, aus der entweder die Drohnen oder die Königinnen (Ligustica) stammen.

Klasse C-II : Anzeichen einer Melanisierung des Mittelstreifens des 3. T. kommt bei reinrassigen Drohnen nicht vor.

Klasse C-III : Ähnelt Klasse A-II, nur der Spiegel ist schon geschlossen.

Klasse C-IV : Im allgemeinen entspricht sie der Klasse A-IV, jedoch enthält der geschlossene Spiegel an der caudalen Seite mehr Melanin.

Klasse C-V : Die Melanisierung des Spiegels des 2. T. schreitet fort, so dass der Spiegel median in zwei Teile geteilt wird. Die Buchten des 2. T. sind melaninfrei. Diese Klasse wurde weder in System A noch in B gefunden.

Klasse C-VI : Die Buchten des 2. T. sind mit Melanin gefült, das jedoch nur eine kleinere Fläche einnimmt, als bei den Ausgangsrassen. Die Melanisierung geht hauptsächlich im Inneren des Spiegels weiter.

Klasse C-VII : Die Sattelfiguren entsprechen Klasse A-VII, nur die Buchtenflächen sind kaum in Richtung des Spiegelvorderrandes und der Flanken verlängert.

Klasse C-VIII : Die Buchtenflächen sind noch schwach entwickelt und nicht mit der Vorder spange verbunden. Der Spiegel des 2. T. ist ganz melanisiert.

Klasse C-IX : Es besteht kein Unterschied zu Klasse A-IX.

Klasse $C-X$ : Ganz melanisiert wie Klasse A-X. 


\section{II. - REZIPROKE KREUZUNGEN}

a) Reziproke Kreuzungen : Ligustica $\times$ Sahariensis $(\mathbf{L} \times \mathbf{S})$ und Sahariensis $\times$ Ligustica $\left(S \times I_{1}\right)$

Die Kreuzung $L \times S$ ergab eine $\mathrm{F}_{1}$-Königin (Nr. $\mathrm{x}$ in Tab. 6), die Drohnen der Klassen C-I bis C-VII erzeugte. Die Mutter dieser Königin war mit einem SahariensisDrohn der Klasse A-VII besamt worden. Aus Abb. I2 ersehen wir, dass die Kurve 2 Maxima enthält. Das erste findet sich in Klasse C-II, das zweite Maximum in Klasse C-VI. Die Mutter B-I39 der Bastard-Königin hatte ihren Ursprung etwa in der Klasse B-II. Diese entspricht im Melanisierungsgrad annähernd der Klasse C-I.

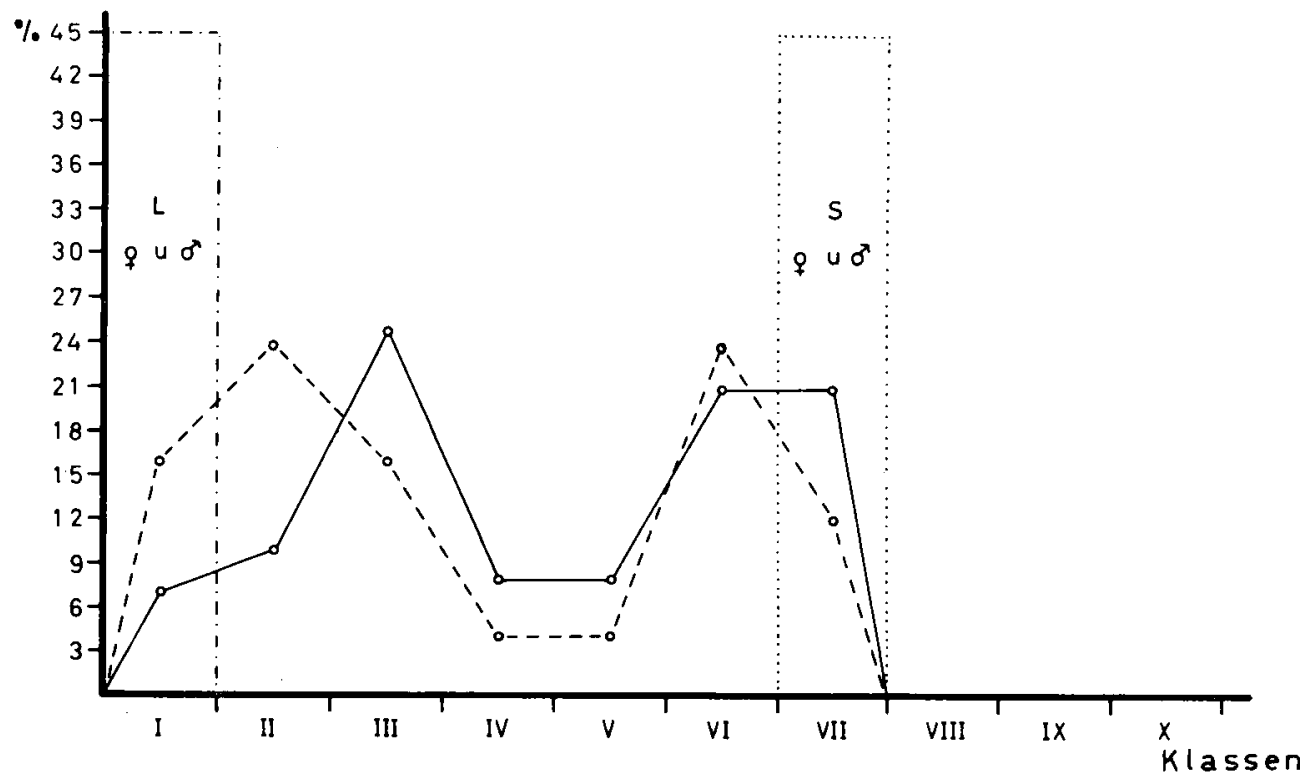

Aвв. I2. - Verleilungskurven der Hybrid-Drohnen der resiproken Kreusungen

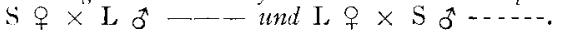

Die eingezeichneten säulen stellen die Klassenzugyehörigkeit der jeweiligen Flterntiere dar Die Klassifizierung der Tergitzeichnungsmuster erfolgt in C-System

F1G. I2. - Répartition des mâles hybrides issus de croisement entre $\mathrm{S}$ 우 $\times$ L $\hat{\sigma}$ et $\mathrm{L}$ 우 $\mathrm{s}$ Les colonnes représentent les groupes auxquels appartiennent les parents La classification des dessins des tergites correspond au système C:

Es findet sich somit in der Nachkommenschaft der Bastard-Königin ein Maximum in der Klassenverteilung nahe der Pigmentierungsklasse ihrer Mutter und eines nahe der Klasse C-VII, der auch der Vater-Drohn der Bastard-Königin angehörte.

Aus der graphischen Darstellung ist klar ersichtlich, dass hier keine eindeutige I : I -Spaltung vorliegt, ebenso ist keine uniforme intermediäre Form vorhanden. Das spricht wieder für die Annahme einer polygenen Basis der Melanisierung des Drohnenabdomens. Wegen der fortgeschrittenen Jahreszeit konnten nur noch 25 Drohnen von der obengenannten Königin beschafft werden. 
Halbiert man die Kurve durch eine senkrechte Linie im Minimum, so werden dem Typ des Sahariensis-I Trohns ca. $42 \%$ der Nachkommen zugeordnet, dem Klassenbereich der Ligustica-Königin sowie ihrer Nachbarklassen ca. $58 \%$.

Bei der Kreuzung $S \times L$ erzeugte die $F_{1}$-Königin Drohnen der Klassen C-I bis C-VII. Die Sahariensis-Mutter-Königin stammte wahrscheinlich aus der Klasse A-VII, der Ligustica-Vater-Drohn aus der Klasse B-II, was etwa der Klasse C-I entspricht. Hier sind ebenfalls 2 Maxima in den Klassen C-III bis C-VI vorhanden. Auch sonst verläuft die Kurve ähnlich wie bei der Kreuzung $L \times S$. Teilen wir die Kurve wie bei der ersten Kombination, erhalten wir an der Seite der SahariensisKönigin $54^{\circ}$ und an der Seite des Ligustica-Drohns $46 \%$ Anteil der Sattelfiguren.

Betrachten wir die reziproken Kreuzungen im Zusammenhang und addieren die Prozente der symmetrischen Teilungen der beiden Kurven, so erhalten wir für die Ligustica-Seite $52 \%$ und für die Sahariensis-Seite $48 \%$ Anteil der Sattelfiguren. Es kann also eine Gruppierung der Nachkommenschaft beider BastardKöniginnen aus reziproken Kreuzungen um zwei Maxima festgestellt werden. Diese Maxima liegen nahe an denjenigen Klassen, aus denen die beiden Elterntiere stammen. In beiden Kurven ist kein dominierender Einfluss des einen Geschlechtes nachweisbar.

\section{b) Reziproke Kreuzungen : Ligustica $\times$ Carnica $(\mathrm{L} \times \mathrm{Ca})$ und Carnica $\times$ Ligustica $(\mathrm{Ca} \times \mathrm{L})$}

Die Kreuzung $L \times C a$ ergab eine $\mathrm{F}_{1}$-Königin, die Drohnen der Klassen C-I bis C-IX produzierte. Die Mutter dieser Königin entstammte der Klasse B-II, was dem Ausmass der Pigmentierung in der Klasse C-I entspricht. Der Vater-Drohn der Königin Nr. 3 in Tabelle 6 gehörte der Klasse A-IX an, die im Melanisierungsgrad der Klasse C-IX gleichzusetzen ist. Die zahlenmässige Aufgliederung der Nachkommen auf die einzelnen Klassen findet sich in $\mathrm{Abb}$. I3.

In der Kurve liegt in Klasse C-III und C-IX je ein Maximum. Durch eine Teilung der Kurve im mittleren. Wert der Klassenverteilung erhalten wir an der Seite der Ligustica-Königin $46 \%$ und im Klassenbereich des Carnica-Vater-Drohns $54 \%$ der Sattelfiguren.

Bei der reziproken Kreuzung $\mathrm{Ca} \times L$ (Königin Nr. 4 in der Tab. 6) entstammte die Cannica-Mutter B IO2 der Klasse A-IX (entspricht der Klasse C-IX) und der Ligustica-Drohn der Klasse B-IV (entspricht C-III). Die Nachkommenschaft verteilt sich iber 7 Klassen von C-III bis C-IX. Die Maxima liegen bei C-IV und C-IX, ein klares Minimum in der Klasse C-VI. Eine Teilung durch den Minimumpunkt ergibt $59 \%$ Carnica-ähnliche Tergitmuster und $4 \mathrm{I} \%$ Ligustica-ähnliche Muster. Werden die Werte aus beiden Kreuzungen addiert und der Mittelwert festgestellt, so liegen die Eirgebnisse bei $57 \%$ Carnica-ähnlichen Nachkommen und bei $43 \%$ Ligustica-ähnlichen Drohnen.

c) Reziproke Kreuzungen : Sahariensis $\times$ Carnica $(\mathrm{S} \times \mathrm{Ca})$ und Carnica $\times$ Sahariensis $(\mathrm{Ca} \times \mathrm{S})$

Bei der Analyse und Klassifikation der Melanisierungsmuster dieser Kreuzungen traten Schwierigkeiten auf, da die Ausgangsköniginnen und -drohnen den stärker melanisierten Klassen des Systems angehörten, d.h. den Klassen A-V und A-X. 


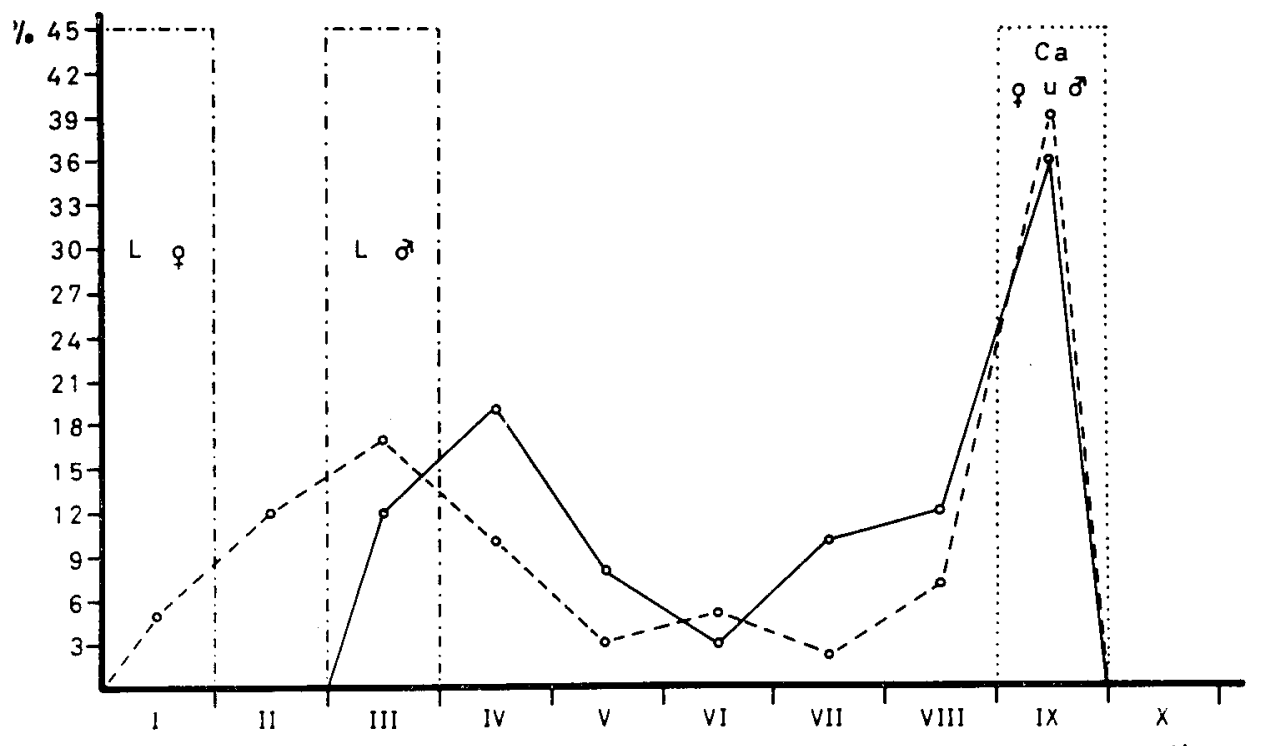

Klassen

ABв. г3. - Verleilungskurven der Hybrid-Drohnen der reziproken Kreuzungen

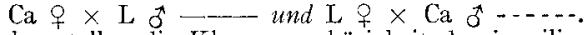

Die eingezeichneten Säulen stellen die Klassenzugehörigkeit der jeweiligen Elterntiere dar

Die Klassifizierung der Tergitzeichnungsmuster erfogt im C-System

FIG, 13. - Répartition des mâles hybrides issus des croisements $\mathrm{Ca}+9 \times \mathrm{L} \delta$ el $\mathrm{L}$ 우 $\times \mathrm{Ca} \sigma \overrightarrow{0}$ Les colonnes représentent les groupes auxquels appartiennent les parents

La classification des dessins des tergites correspond au sytème C

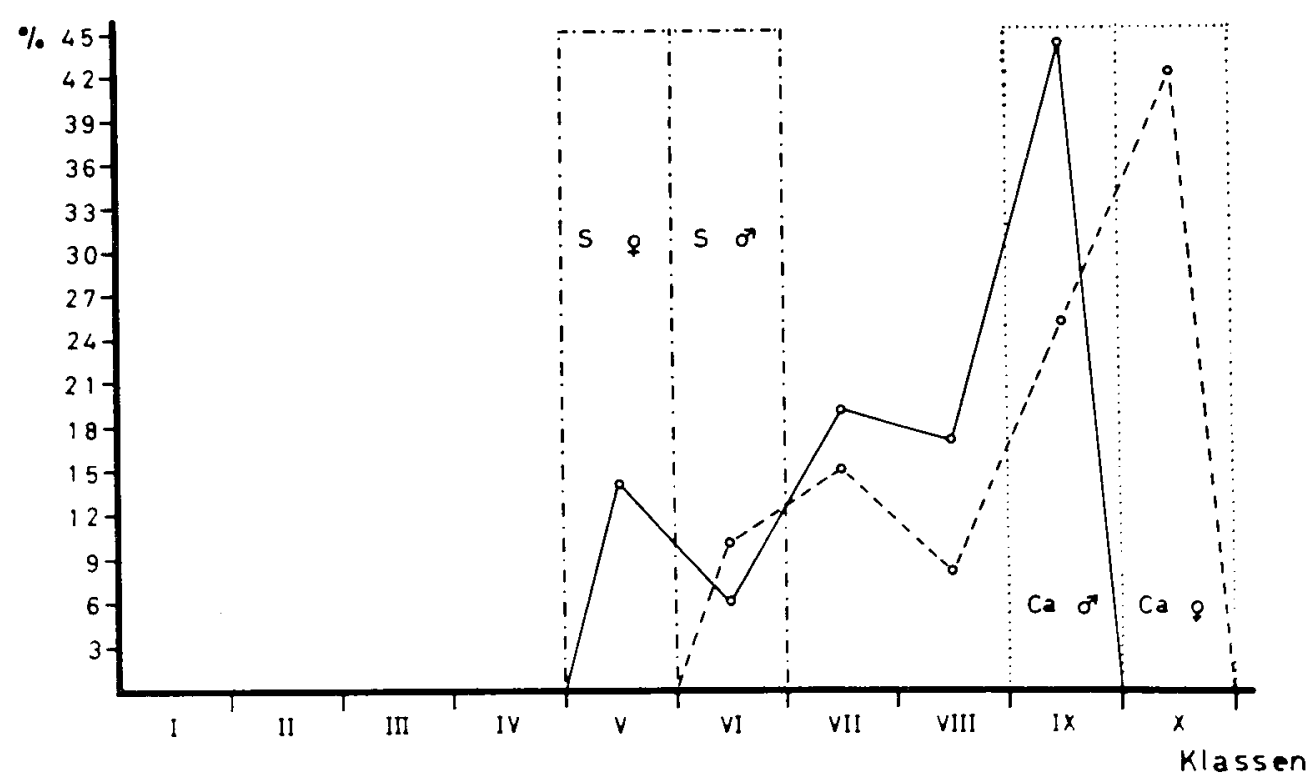

Aвв. 14. - Verteilungskurven der Hybrid-Drohnen der reziproken Kreuzungen

$$
\mathrm{S} q \times \mathrm{Ca} \sigma \ldots \text { und } \mathrm{Ca} \text { o } \times \mathrm{S} \delta \text {-.... }
$$

Die eingezeichneten Säulen stellen die Klassenzugehörigkeit der jeweiligen Elterntiere dar Die Klassifizierung der Tergitzeichnungsmuster erfolgt im C-oder A-Klassensystem

FIG. 14. - Répartition des mâles hybrides issus des croisements $\mathrm{S}$ 우 $\times \mathrm{Ca}$ कै et $\mathrm{Ca}$ 우 $\times \mathrm{S} \hat{q}$ Les colonnes représentent les groupes auxquels appartiennent les parents

La classification des dessins des tergites correspond aux systèmes C ou A 
So ergab sich bei der ersten Kreuzung einer Sahariensis-Königin (Königin Nr. 5 in Tab. 6), die der Klasse A-V einzuordnen war, mit einem Camica-Drohn aus Klasse A-IX in der Nachkommenschaft eine abweichende Verteilung (Abb. I4). Ein Maximum lag in Klasse A-IX. Die in den Klassen IV bis VIII einzustufenden Nachkommen wiesen starke Melanisierung auf, so dass man sie dem A-Klassensystem zuordnen konnte. Es fehlte bei dieser Kreuzung sowohl ein ausgeprägtes zweites Maximum in der Nähe der Melanisierungsklasse der Sahariensis-Königin als auch das bei den Kreuzungen $S \times L$ und $C a \times L$ nachzuweisende Minimum.

In der reziproken Kreuzung, bei der die Carnica-Königin aus Klasse A-X und der Sahariensis-Drohn aus der Klasse A-IV war, ist ebenfalls nicht die typische Kurvenform zu finden. In beiden Fällen dominiert der dunklere, d.h. der stärker melanisierte Carnica-Typ eindeutig. Dabei ist es belanglos, ob von der CarnicaRasse der männliche oder weibliche Kreuzungspartner stammte.

\section{III. - DISKUSSION}

Die Errgebnisse des zweiten Teiles können bei der Komplexität der Musterausbildung des Drohnen-Abdomens nur beschreibender Natur sein. Bisher liegen auch keine austeichenden Ergebnisse anderer Autoren vor, die einen Vergleich ermöglichen könnten.

Eis lässt sich jedoch feststellen, dass bei der Kreuzung von Vertretern aus zwei verschiedenen Klassensystemen $(S \times L$ und $C a \times L)$ für die Klassifizierung der Bastard-Drohnen in den mittleren Klassenstufen die Ausgangssysteme der A- und B-Klassen nicht ausreichend sind. Zur Einstufung dieser Pigmentmuster war die Einführung eines weiteren Systems (System C) erforderlich.

Für die Kreuzung von zwei Rassen desselben Klassensystems $(\mathrm{Ca} \times \mathrm{S})$ reicht das elterliche Klassensystem auch für die Einstufung der Nachkommen aus. Hier ist jedoch zu berïcksichtigen, dass die Drohnen wegen der starken Melanisierung der Ausgangstiere alle in den Klassenbereich A-V bis A-IX einzuordnen sind, in dem überdies zı den Klassen des C-Systems starke Übereinstimmung mit den Klassen des A-Systems herrscht.

Eine Abschätzung der der Musterbildung zugrunde liegenden genetischen Basis ist auf Grund des unzureichenden Materials nicht möglich.

In der Arbeit von Roberts (I950, zit. bei RoBerTs u. MACKENSEN I95I) wird von Untersuchungen ïber die Pigmentierungs-Intensität nach Kreuzung von sehr hellen mit dunklen Bienenstämmen, die jedoch nicht einer definierten geographischen Rasse angehörten, berichtet. Die Kreuzungen wurden mit Hilfe der instrumentellen Besamung durchgeführt und sind daher einwandfrei in Hinsicht auf die Kontrolle der Paarungen. Bei der Einstufung der Nachkommen fand jedoch lediglich der Helligkeitsgrad Berücksichtigung, die feinere Ausbildung des Melaninmusters beachtete man nicht. Eine Abschätzung der beteiligten Erbträger führte zur Annahme von 7 Genpaaren für die Ausbildung der abdominalen Ausfärbung. RoBERTs stellte in seiner Arbeit auch einen kontinuierlichen Übergang von hell zu dunkel fest. Eine Häufung einzelner Typen mit bestimmtem Melanisierungsgrad wurde nicht konstatiert. Meine Befunde, dass nach Kreuzungen von hellen und dunklen Elterntieren 
aus verschiedenen Rassen bei den Bastard-Drohnen zwar alle Zwischenklassen der Melanisierung, jedoch eine Häufung von Exemplaren nahe der Klassen der beiden Elterntiere der Hybrid-Königin nachweisbar ist, liefert vielleicht eine Erklärung für die unterschiedlichen Beobachtungen früherer Autoren nach Rassenbastardie rungen. Bei diesen älteren Beobachtungen muss aber berïcksichtigt werden, dass hier fast immer ein Rïckschluss von den beobachtbaren Ergebnissen, das heisst der Nachkommen auf die Partner der nicht zu beobachtenden Paarung erfolgte. Heute sind wir über die früher unbekannte Mehrfachpaarung der Bienenkönigin unterrichtet und müssen daher die Mitteilungen genetisch-züchterischer Art bei der Honigbiene aus den Jahren vor $1955 \mathrm{kritisch}$ beurteilen.

DzIERZON (zit. bei ARMBruSTER, I935) berichtete von der männlichen Nachkommenschaft einer Mellifica-Ligustica Bastard-Königin, es sei eine Aufspaltung in Mellifica- und Ligustica-Drohnen erfolgt. Bei einer wenig differenzierenden Analyse des Melanisierungsmusters mag durch die Häufung der Nachkommen in zwei Maxima diese Schlussfolgerung verständlich sein. Nach seinen Beobachtungen von der Verteilung der Sohn-Drohnen einer Mellifica-Ligustica Bastard-Königin glaubte NEWEI,I. (I9I5) die DzIERzon'sche Feststellung bestätigt zu finden. In einer Prüfung den Nachkommenschaft von Caucasica-Nigra Bastard-Königinnen fand ZANDER (I923) eine starke Aufspaltung der Drohnen; detailliertere Angaben wurden nicht gemacht. Als Eirgebnisse seiner Untersuchungen über die Aufspaltung der DrohnenNachkommenschaft von Bastard-Königinnen betonte Armbruster (I923) das Überwiegen des mütterlichen Einflusses. Die von LAIDLAW u. EL BANBY (I962) und EI. BANBY (I965) beobachtete Überdeckung der dunklen Ausfärbung durch gelbe, bei $\mathrm{F}_{1}$-Generation Arbeiterinnen, und die darauffolgende Aufspaltung der HybridDrohnen von Nachzuchtköniginnen im Verhältnis I : I konnte ich nicht feststellen.

Wenn auch die zum Teil individuenmässig unzureichenden Drohnenproben eine quantitative genetische Analyse nicht ermöglichen, so lässt sich doch aussagen, dass die beiden "Elterntypen-Maxima ", wenn man durch das Minimum eine senkrechte Trennungslinie zieht, dem Verhältnis $I: I$ recht nahe kommen. Trotzdem besteht in beiden Teilen ein klarer polygener Einfluss der Eiterntiere. Meine Befunde bestätigen nicht eine stärkere Matroklinie. Diese Verschiebung besprochener Verhältnisse tritt auf bei der reziproken Kreuzung von Exemplaren, die zwei dunklen Rassen angehören $(\mathrm{Ca} \times S$ und $S \times C a$ ). Hier zeigen die reziproken Kreuzungen nur ein Übergewicht der dunkleren- in diesem Falle Carnica-Form. Der dominierende Einfluss war jedoch unabhängig vom Geschlecht des stärker melanisierten Partners.

Reçu pour publication en février 1966

\section{DANK}

Das Thema dieser Arbeit wurde mir von Herrn Prof. Goetze gegeben und der Fortgang der Untersuchungen von ihm mit Interesse verfolgt.

Die im Manuskript mitgeteilten Untersuchungsergebnisse lagen beim Tod von Herrn Prof. GoET2E im Frühjahr I 965 in dieser Form vor.

Für die Hilfe bei der Herstellung der Zeichnungen und Tabellen sei Fräulein B. RaPPE an dieser Stelle gedankt. Herrn Dr. W. Drescher danke ich für die Durchsicht des Manuskriptes. 


\section{ZUSAMMENFASSUNG}

In der vorliegenden Arbeit wurde eine eingehende Phänoanalyse der Abdominal-Tergite von Jrohnen folgender geographischer Rassen durchgeführt : Carnica, . Hellifica (Nigra), Caucasica, Persica, Amenica, Ligustica, Sahariensis, Fasciata und Cypria. Anschliessend erfolgten mit Hilfe der künstlichen Samenübertragung die reziproken Kreuzungen der Rassen : Sahariensis $\times$ Ligustica, Carnica $\times$ Ligustica und Sahariensis $\times$ Carnica.

Zur Inalyse und Beschreibung der dunklen Melaninmuster auf gelbem Untergrund wurde das 2. - 5. Tergit präpariert und gezeichnet. Unter der Berücksichtigung der bereits vorhandenen, älteren Nomenklatur mussten zur eingehenden Klassifizierung einige Begriffe neu eingeführt werden. Die Zeichnungen der mehr als I 300 Exemplare der Drohnen verschiedener geographischer Rassen und Rassenkreuzungen wurden so angeordnet, dass eine kontinuierliche Reihe in der Ausbildung des dunklen Farbmusters der Abdominal-Tergite entstand.

Für die geographischen Rassen : Carnica, Mellifica (Nigra), Caucasica, Persica, Armenica, Sahariensis, Fasciata und Cypria reichte eine ro-klassige Einteilung zur Erfassung der hervorstechenden Veranderungen aus. Diese Klassifizierung be\%eichnete ich als A-System.

Die Tiere der Ligustica-Rasse verlangten für sich ein eigenes System (System B). Ls wurde erforderlich. weil bei dieser Rasse im Bereich der helleren Klassen der T'ergitausfärbung keine Übereinstimmung mit den Tieren von System A bestand.

Hier lässt sich jedoch nicht einwandfrei klären, inwieweit das Melanisierungsmuster der hellen Stufen durch züchterische Selektion der imkerlich bevorzugten, helleren Formen bedingt ist. Für die Einordnung von dunkleren Ligustica-Material stand nicht eine ausreichende Anzahl Drohnen zur Verfügung. Die wenigen dunklen Exemplare der Klassen BVII-BIX zeigten starke Annäherung an die andersrassigen Tiere der entsprechenden Melanisierungsklassen des A-Systems.

Bei der Klassifizierung der Zeichnungsmuster der Hybrid-Drohnen wurde die Einführung eines weiteren Klassensystems (System-C) notwendig, weil besonders bei den Kreuzungen zwischen Elterntieren aus verschiedenen Systemen $Z$ wischenformen auftraten, die sich nicht in die Klassen der Ausgangssvisteme einfügten.

Die Festlegung der vorgenannten io Klassen mussten notwendigerweise willkürlich und subjektiv erfolgen, da zwischen den ausgewählten Melanisierungsklassen gleitende Übergänge nachweisbar sind.

Bei den zum System A gehörenden Rassen wurde konstatiert, dass jede geographische Rasse in diesem System in Hinsicht auf das Zeichnungsmuster der Drohnenabdomens einen bestimmten Bereich des gesamten möglichen Musterspektrums einnimmt. Diese rassetypischen Bereiche überschneiden sich jedoch erheblich und lassen dadurch eine Trennung der geographischen Rassen allein auf Grund der Musterbildung der Drohnentergite nicht zu. Dabei nahm Persica das ganze Spektrum ein, während sich die übrigen Rassen in eine Reihe von Fasciata über Cypria, Sahariensis, Armenica, Carnica, zu Caucasica und Mellifica (Nigra) mit zunehmender Dunkelfärbung einordnen liessen.

Für die reziproken Kreuzungen fanden jeweils zwei in ihrer Ausfärbung bekannte Elterntiere Verwendung. Es wurde die Häufigkeitsverteilung der Nachkommen innerhalb des Klassensystems geprüft.

Nach Kreuzungen von Elterntieren sehr unterschiedlicher Melanisierung wurden bei den Bastard-Drohnen alle Zwischenklassen der Ausfärbung gefunden. Eine Anhäufung von Nachkommen nahe den Klassen der beiden Elterntiere der Hybridkönigin wurde festgestellt, wie aus den zweigipfeligen Verteilungskurven aller reziproken Kreuzungen ersichtlich ist.

Die Annahme früherer Autoren von einer Spaltung der Nachkommen nach Rassenkreuzungen im Verhältnis I:I ist vermutlich durch zu einfache Betrachtung der Bastarde ohne eine stärker differenzierende Analyse des Melanisierungsmusters entstanden. Die Häufigkeitsverteilung der Drohnen innerhalb der Stichproben geographischer Rassen und der Nachkommen von Rassenkreuzungen sprechen für eine polygene Basis der Musterausbildung des Drohnenabdomens.

Bei den reziproken Kreuzungen zeigte sich allgemein keine stärkere Matroklinie in der Vererbung des Melanisierungsmusters. Ein dominierender Finfluss des dunkleren Partners war nachweisbar. 


\title{
RÉSUMÉ
}

\author{
La PHÉNO-ANALYSE DES TERgITES ABDOMINAUX DES MALES \\ DE DIFFÉRENTES RACES GÉOGRAPHIQUES DE L'ABEILLE. (APIS MLELIFICA L.) \\ ET DE LEURS CROISEMENTS
}

Le présent travail débute par une phéno-analyse des tergites abdominaux chez les mâles des races géographiques suivantes : Carnica, Mellifica (Nigra), Caucasia, Persica, Armenica, Ligustica, Sahariensis, Fasciata et Cypria. L'auteur analyse ensuite les tergites abdominaux des mâles provenant de croisements réciproques entre deux races, obtenus par insémination artificielle. Il s'agit des croisements suivants : Sahariensis $\times$ Ligustica; Carnica $\times$ Ligustica et Sahariensis $\times$ Carnica .

Quatre tergites (du $2^{\mathrm{e}}$ au $5^{\mathrm{e}}$ ) ont été préparés et dessinés afin de permettre l'analyse des dessins de mélanine sur fond jaune. Pour avoir une classification exacte il a été nécessaire d'introduire quelques définitions nouvelles, tout en conservant les termini technici et les définitions des auteurs précédents. Les dessins de plus de I 300 mâles et races géographiques différentes et issus de croisements entre races, ont été répartis de façon à montrer une série continue dans la formation du pigment sombre des tergites abdominaux.

Pour les races géographiques suivantes : Carnica, Mellifica (Nigra), Caucasica, Persica, Armenica, Sahariensis, Fasciata et Cypria, une répartition en ro classes a suffi pour comprendre les variations prédominantes. Cette classification est nommée système A.

Pour les insectes de la race Ligustica il a fallu un système particulier (système B), la couleur des tergites n'ayant pas de rapport avec celle des insectes du système $\mathrm{A}$ dans les classes les plus claires.

On ne peut déterminer exactement dans quelle mesure les dessins de mélanine des degrés clairs sont conditionnés par la prédilection des apiculteurs pour les formes claires et par leur sélection.

L'auteur n'a pas pu réunir un assez grand nombre de mâles sombres de race Ligustica pour les ranger dans la série. Les quelques exemplaires des groupes B-VII à B-IX montrent une nette parenté avec les animaux des autres races appartenant aux groupes correspondants du système A.

Un troisième système (système $\mathrm{C}$ ) a été nécessaire pour classer les dessins de mâles hybrides car il existe des formes intermédiaires, surtout dans les croisements d'animaux provenant de systèmes différents. Les formes intermédiaires ne se laissent pas insérer dans les classes du système de base.

L'arrangement des io classes déjà mentionnées est nécessairement arbitraire et subjectif comme le montrent les transitions entre les groupes de mélanine choisis.

En ce qui concerne les dessins de l'abdomen, l'auteur constate que chaque race géographique occupe une partie déterminée du spectre des formes possibles. Ces parties caractéristiques des races se chevauchent considérablement et ne permettent pas une division des races fondée uniquement sur la formation des dessins sur les tergites des mâles. Ainsi Persica occupe tout le spectre, tandis que les autres races peuvent être classées en une série de plus en plus foncée allant de Fasciata en passant par Cypria, Sahariensis, Armenica, Camica, jusqu'à Caucasica et Mellifica (Nigra).

Pour les croisements réciproques on a utilisé chaque fois deux animaux de couleur connue. On a déterminé chez les descendants le nombre d'individus de chaque classe du système.

Des croisements entre parents de couleur très différente ont donné des mâles qui avaient toutes les colorations intermédiaires.

Les courbes de distribution de croisements réciproques montrent une accumulation des descendants au voisinage des classes des deux parents d'une reine hybride. L'hypothèse de certains auteurs selon laquelle, après des croisements de race, les descendants se divisent dans le rapport I : I est due sans doute à un examen trop rapide des bâtards et du dessin de mélanine. La fréquence de répartition des individus à l'intérieur des races géographiques et chez les descendants issus de croisements interraciaux, laisse supposer une base polygène dans la formation des dessins de l'abdomen chez les mâles. Lors des croisements, on n'a pas constaté de prépondérance des caractères maternels (matroclinie) dans la transmission du dessin de mélanine. L'influence dominante du partenaire plus foncé a été mise en évidence. 


\section{SUMMARY}

PIENO-ANALYSIS OF THE ABUOMINAL TERGITES

OF THE MALES OF DIFFERENT GEOGRAPHICAL RACES

AND CROSSINGS OF THE BEE (APIS MELLIFICA L.)

This work began with a pheno-analysis of the abdominal tergites of the males of the following geographical races : Carnica, Mellifica (Nigra), Caucasia, P'ersica, Armenica, Ligustica, Sahariensis, Fasciata and Cypria. An analysis was then made of the abdominal tergites of males from reciprocal crossings between two races, effected by artificial insemination. The following crossings were used : Sahariensis $\times$ Ligustica, Carnica $\times$ Ligustica, and Sahariensis $\times$ Carnica.

Four tergites were prepared (the second to the fifth), and they were drawn on a yellow background for analysis of the melanin patterns. In order to have an exact classification, it was necessary to add some new definitions to the terms and definitions given by previous authors. The patterns of more than I 300 males were assessed, both from different geographical races and from the issue of crossings between races, and they were found to comprise a continuous series.

For the following geographical races - Carnica, Mellifica (Nigra), Caucasia, Persica, Armenica, Sahariensis, Fasciala, and Cypria - a division into ten classes was sufticient to identify the predominant variations. This classification was called System $A$.

A special system (System B) was needed for the insects of the Ligustica race, since the colour of the tergites in the lightest coloured classes had no relation to that of the insects in System $\mathrm{A}$. However, it cannot be exactly determined to what extent the patterns of the light coloured categories are conditioned by the predilection of apiarists for light coloured forms, and to what extent by selection.

It has not been possible to collect a large enough number of dark males of the Ligustica race for them to be included in the series. The few examples of the groups BVII to BIX show a clear relationship to the bees of the other races belonging to the corresponding groups in System $A$.

A third system (System C) was necessary for classifying the patterns of male hybrids, since there exist intermediary forms, especially in the crossings of bee from different systems. The intermediary forms cannot be included in the classes of the basic system.

The arrangement of the ten classes already mentioned is necessarily arbitrary and subjective, as is shown by the transitions between the melanin groupings chosen.

With regard to pattern on the abdomen, it was shown that each geographical race occupies a fixed portion of the range of possible forms. These parts are characteristic of the race but overlap considerably, and they do not allow division into races solely on the patterns on the tergites of the males. Thus Persica covers the whole range, whilst the other breeds can be classified in a series of increasing darkness, starting from Fasciata, passing through Cypria, Sahariensis, Armenica, and Carnica, and extending to Caucasia and Mellifica (Nigra) at the extreme.

For reciprocal crossings, two bees of known colour were used each time, and the number of descendants falling into each class of the system was determined.

Crossings between parents of very different colour gave males with all intermediary colours. The distribution curves show an accumulation of descendants similar to the classes of the two parents of a hybrid cueen. The hypothesis of certain authors that, after crossings between races, the descendants are grouped in a I:I ratio is doubtless due to a too hasty examination of bastards and of the melanin pattern.

The distribution within geographical races and among the descendants of interracial crossings suggest that there is a polygenic basis for the formation of the pattern on the abdomen of males. During the crossings, no preponderance of maternal characteristics (matrocliny) was shown in the transmission of the melanin pattern, and the dominant influence of the darker partner was established.

\section{LITERATURVERZEICHNIS}

ADAM Brother, 195 I. In search of the best strains of bees. Bee World, 32, 49-52, 57-62.

ADam Brother, 196I. In search of the best strains of bees. Third journey : The Iberian Peninsula. Bee

World, 42, 123-131.

ADAM Brother, 1964. Auf der Suche nach den besten Bienenstämmen. Stidwestdtsch. Imker, 16, 212-215.

Aday Brother, 1965. Auf der Suche nach den besten Bienenstämmen. Sülwestdtsch. Imker, 17, 14-17. 
Alber M., I952. Imkerbummel in Algerien. Disch. Bienenwivtschaft, 3, 204-208.

Alber M., Jordan, R., Ruttner F. u. H., I955. Von der Paarung der Honigbiene. Z. Bienenforsch., 3, I-28.

ARMbruster L., I9I9. Bienenzüchtungskunde. Theodor Fischer Verlag Berlin.

Armbruster L, 1923. Wie untersucht man Bierenstämme und Bienenkreuzungen auf ihre Farbe? Arch. Biencnkde, 5, 97-123.

Armbruster L., i935. Hundert Jahre Parthenogenesis. Dzierzon : Der sparsame Bienenkönicr. Arch Bienenkde, 16, 283-31.

Baldensperger Ph. J., i933. Variétés d'abeilles en Afrique du Nord. Ve Congrès Intern. d'Entomol., Paris I932. II. Travaux $829-839$.

BAKk F.. I955. Rassenuntersuchungen an der ungarischen Ilonigbiene (ungar). Méhészet, 3, 223-227 (Ref. Bce World, 38, 79).

Beldame R., 1951. Un progres important a réaliser. Gazelle Apicole, 6, I66.

BerG A. H. v. d., I957. Raskenmerken bij Honingbijen. Maandschrift voor Bijenleell, 59, $212-2$ I 4.

Boverl 'Th., I915. T'ber die Entstehung der Iugsterschen Zwitterbienen. Arch. Entwickl. Mech., 41, 26+3I I.

Buttel-Reepen H. von, igo6. Apistica. Mill. Zool. Mus. Berlin, 3, (2).

BUTTEL-REeper H. von, I921. Zur Lebensweise der ägyptischen Biene (A. mell. fasciata) sowie einiges zur Geschichte der Bienenzucht. Arch. Bienenkde, 3, 19-67.

EL-BANBY A. M., 1963. Biometrical investigations on the egyptian honeybee. XIXIh Intern. Beekeep. Congr. Prag, $7^{-8}$.

Ji-BANBY A. M., I965. Die Vererbung der Unterleib-Wechselbeziehung bei den Mestizen der CarniolischAgyptischen. Apimondia $\mathrm{I} / \mathrm{I}$. Inlern Kongress Bukarest.

Farcas A., 1938. Contributiuni la studiul culorii albinelor (rumän). Bull. Facull. Agron. Din Cluj, 7, 4-9. Fistear; J. N., 1937. Cercetări biometrice la albinele romanesti. Diss. Veterinär.-Medic. Fukull. Univ. Bukaresi.

Gerstäcker A., s 862. Über die geographische Verbreitung und die Abänderungen der Honigbiene der Alten Welt. (Bei ButTEL-ReEpeN) 1906.

Giamarixi I.. I953. Ricerce sui caratteri razziali dell' Apis m.ligustica spinola. Mem. Soc Entomol. Italia 32, I $20-1.39$.

Goetze (i., I 930. Variabilitäts- und Züchtungsstudien an der Honigbiene mit besonderer Berücksichtigung der Langrüsseligkeit. Arch. Bienenkde. 11, I35-274.

Goetze G., 1938. Die greographischen Rassen der Honigbiene und die Zuchtbestrebungen der Reichsfachgruppe Inker. VII. Intern. Kongr. Enlom. Berlin, 3, I792-1 Bo I.

Goetze (i., 1950. Monographie der Carnica-Biene. Imme 2, I26-184.

Goetze G., I95I. Zur Farbanalyse der Abdominal-Tergite der Drohnen der Italiener-Biene. (Apis $m$. var. ligustica SPIN.) Imme, 3, $230-234$.

Goztze G., Ig64. Die Honigbiene in natürlicher und künstlicher Zuchtauslese. Teil I. Beihefte zur $Z$. angea. Entomol., 19, I-I 20.

Goetze G., 1964. Die Honigbiene in natürlicher und künstlicher Zuchtauslese Teil II. Beihefte zur $Z$. Entonol., 20, I-92.

Haccolr P., I960. Investigations on the Sahara bee in Morocco. C. R. Soc. Sci. nat. Maroc, 6, 96-98.

Hassanein M. H., Ei-Banby M. A., 1956. Studies on the biometrics of the Egyptian honeybee (Apis m. fasciata LATR.) Bull. Soc. Enlomol. Egyple 40, i $27^{-1} 30$.

Kascheff A. H., 1959. The single strain of the Fgyptian honeybee. Insectes Sociaux, 6, $243-257$.

Katogjan A., 1963. Charakteristik der Honigbiene. Vollst. T'exie der Vorlräge XIX. Apimondia-Kongr. I 963 , II. Teil, $23 \mathrm{I}^{-2} 35$.

Kerr W. E., De-Portugal A. V., 1958. Racas de abelhas de Africa. (portug.). Garcia de Oria, 6, 53-59.

LAIDLAW H. H., EL-BANBY A. I., I 962. Inhibition of yellow body color in honeybee. J. Heredity, 8, (7-8) I 7 I-I 73 .

Mackensen O., I943. The occurrence of parthenogenetic females in some strains of honeybees. J. econ. Entonol, 36, 465-467.

Mackevsen O., Roberts W. C., I948. Manual for the artificial insemination of queen bees. U. S. Bureau Ent. E. T., 250, I-33.

Markosjan Z., ig6o. Einige Merkmale der armenischen Bienen. (russ.). Ptschelowodstwo, 8,

Neweil W., r9I5. Inheritance in the honey bee. Science, 41, 218-2 I9.

Peer D. F., r956. Multiple mating of queen honeybees. J.econ. Entomol, 49, I32.

Rihar J., I96I. Recherches biométriques sur la couleur des abeilles carnioliennes en Yougoslavie. Ann. Abeille, 4, 4I-5o.

Roberts W. C., I950. (Dissertation). Summary and Conclusions (Univ. of Wisconsin for Ph. D. Examination). 
Roberts W. C., Mackensen O., I95I. Breeding improved honcy bees. Amer. Bee. J., 91, 292-294, 32 S$330,382-384,418-421,473-475$.

RotTer E., Igrg. Die Goldbienen. Disch. Imker aus Böhmen, 32, г за.

RotTer E., I92I. Die ägyptische Biene (Apis m. fasciata LATr.). Arch. Bienenkde, 3, I-8.

Ruttner F., I95I. Das Gelb der Carnica. Bienermü̈lterchen, (го).

RUtTNer F., I963. Die künstliche Besamung der Bienenkönigin als Voraussetzung für die Selektion und Vererbungsstudien. XIX. Intern. Kongr. Prag, II. Band.

Ruttner F., I963. Die Zuchtauslese bei der Biene. Verlag Nö. Imkerschule Wr. Neustadt.

Ruttner F., und H., Ig62. Genetische Analyse der braunen Zeichnungsmuster am Abdomen von Carnica Bienen. Bee-Genetics information Bull., 3, 18.

SkoRIKow A., I929. Beiträge zur Kenntnis der kaukasischen Honigbiene. (russ.). Ber. Buros. angezo. Entomol, 4, I-5.

Skorikow A., I929. Eine neue Basis für eine Revision der Gattung Apis L. Rep. appl. Enionol, 4, 249270.

Sмiтн F. G., I961. The races of honeybees in Africa. Bee World, 42, 255-260.

SNodgrass R., 1956. Analomy of the honeybee. Comstock Publishing Associates, Ithaca, New York.

Soose E. 1954. Einfluss der Temperatur auf die Ausgestaltung von Flügelindex und l'anzerfarbe der Honigbiene (Apis mell.). Arch. Bienenkde. 31, 50-66.

TABER S. III, I954. The frequency of multiple mating of queen honeybees. J. econ. Entomol, 47, 995-998. TEMPI.ER C. R., I957. Beekeeping in the Canary Islands. Bee World, 38, I84.

Wertheim G., 1940. Some remarks on the race of the Palestinian honey bee. Bee Kingdom, 11, 281-283.

ZANDER E., I92I. Beiträge zur Rassenunterscheidung der Honigbiene (Apis mell. L.) Arch. Bienenkde, 3, I $53^{-1} 7^{6}$.

ZANDER E., I923. Beiträge zur Variabilität und Vererbung bei der Honigbiene. Erlanger Jb. Bienenkde. $1,5-66$.

ZaNDer E., Weiss K., I964. Das Leben der Biene. Verlag Eugen U1ner, Stuttgart. 